\title{
On the drivers of inter-annual and decadal rainfall variability in Queensland, Australia
}

Article

Published Version

Klingaman, N., Woolnough, S. and Syktus, J. (2013) On the drivers of inter-annual and decadal rainfall variability in Queensland, Australia. International Journal of Climatology, 33 (10). pp. 2413-2430. ISSN 0899-8418 doi:

https://doi.org/10.1002/joc.3593 Available at https://centaur.reading.ac.uk/29209/

It is advisable to refer to the publisher's version if you intend to cite from the work. See Guidance on citing.

Published version at: http://onlinelibrary.wiley.com/doi/10.1002/joc.3593/abstract

To link to this article DOI: http://dx.doi.org/10.1002/joc.3593

Publisher: John Wiley \& Sons

All outputs in CentAUR are protected by Intellectual Property Rights law, including copyright law. Copyright and IPR is retained by the creators or other copyright holders. Terms and conditions for use of this material are defined in the End User Agreement.

\section{www.reading.ac.uk/centaur}

\section{CentAUR}

Central Archive at the University of Reading 
Reading's research outputs online 


\title{
On the drivers of inter-annual and decadal rainfall variability in Queensland, Australia
}

\author{
N. P. Klingaman, ${ }^{a, b *}$ S. J. Woolnough ${ }^{\mathrm{a}, \mathrm{b}}$ and J. Syktus ${ }^{\mathrm{c}}$ \\ ${ }^{a}$ National Centre for Atmospheric Science-Climate, Reading, UK \\ ${ }^{\mathrm{b}}$ Walker Institute for Climate System Research, University of Reading, Reading, UK \\ ${ }^{c}$ Queensland Climate Change Centre of Excellence, Dutton Park, Queensland, Australia
}

\begin{abstract}
Queensland experiences considerable inter-annual and decadal rainfall variability, which impacts waterresource management, agriculture and infrastructure. To understand the mechanisms by which large-scale atmospheric and coupled air-sea processes drive these variations, empirical orthogonal teleconnection (EOT) analysis is applied to 1900-2010 seasonal Queensland rainfall. Fields from observations and the 20th Century Reanalysis are regressed onto the EOT timeseries to associate the EOTs with large-scale drivers. In winter, spring and summer the leading, state-wide EOTs are highly correlated with the El Niño-Southern Oscillation (ENSO); the Inter-decadal Pacific Oscillation modulates the summer ENSO teleconnection. In autumn, the leading EOT is associated with locally driven, late-season monsoon variations, while ENSO affects only tropical northern Queensland. Examining EOTs beyond the first, southeastern Queensland and the Cape York peninsula emerge as regions of coherent rainfall variability. In the southeast, rainfall anomalies respond to the strength and moisture content of onshore easterlies, controlled by Tasman Sea blocking. The summer EOT associated with onshore flow and blocking has been negative since 1970, consistent with the observed decline in rainfall along the heavily populated coast. The southeastern Queensland EOTs show considerable multi-decadal variability, which is independent of large-scale drivers. Summer rainfall in Cape York is associated with tropical-cyclone activity. Copyright (C) 2012 Royal Meteorological Society
\end{abstract}

KEY WORDS rainfall; Queensland; teleconnections; variability; decadal; inter-annual; El Nino Southern Oscillation

Received 23 May 2011; Revised 22 June 2012; Accepted 9 August 2012

\section{Introduction}

1.1. Inter-annual and decadal variability in Queensland's rainfall

The state of Queensland, in northeastern Australia, has experienced substantial inter-annual and decadal rainfall variability since reliable observations began in the late nineteenth century (Lough, 1991; Lavery et al., 1997; Hennessy et al., 1999). Analysis of the SILO kriged gauge rainfall product (Jeffrey, 2001), described in Section 2.1, reveals alternations between multi-year periods of above- and below-normal rainfall (Figure 1). The timeseries in Figure 1 uses May-April annual means, since the Queensland wet season spans November-April; the state receives approximately $80 \%$ of its annual rainfall in those 6 months. These inter-annual and decadal rainfall variations are far larger and have greater socio-economic impacts than any linear trends in seasonal or annual rainfall, which are small and statistically insignificant for Queensland as a whole (Nicholls and Lavery, 1992). Rainfall along the eastern coast of Australia, including coastal Queensland, has decreased since the 1950s

* Correspondence to: N. P. Klingaman, Department of Meteorology, University of Reading, P.O. Box 243, Reading, Berkshire RG6 6BB, UK. E-mail: n.p.klingaman@ reading.ac.uk
(Alexander et al., 2007; Gallant et al., 2007), but it is unclear whether the decline has resulted from (1) an externally forced shift in the climatological rainfall (i.e. from anthropogenic climate change), or (2) the negative phase of a natural, multi-decadal or centennial oscillation (Cai et al., 2001).

This study aims to identify and understand the influences of atmospheric and coupled atmosphere-ocean drivers on inter-annual and decadal rainfall variability in Queensland. An improved knowledge of the impacts of these drivers would aid rainfall predictions on temporal scales of one season or longer, as at these lead times models often have considerably more skill at predicting large-scale atmospheric variability than regional rainfall patterns. Improved predictions would aid efforts to mitigate the impacts of rainfall variability on agriculture, hydrology and infrastructure in Queensland. Conclusions from this work may also give insight into likely changes in Queensland's rainfall over the next several decades, which are critical for water-resource management.

\subsection{Drivers of inter-annual and decadal rainfall variability}

Inter-annual and decadal variability in Queensland's rainfall has been strongly linked to the El Niño-Southern Oscillation (ENSO; e.g. Allan, 1988; Wang and Hendon, 


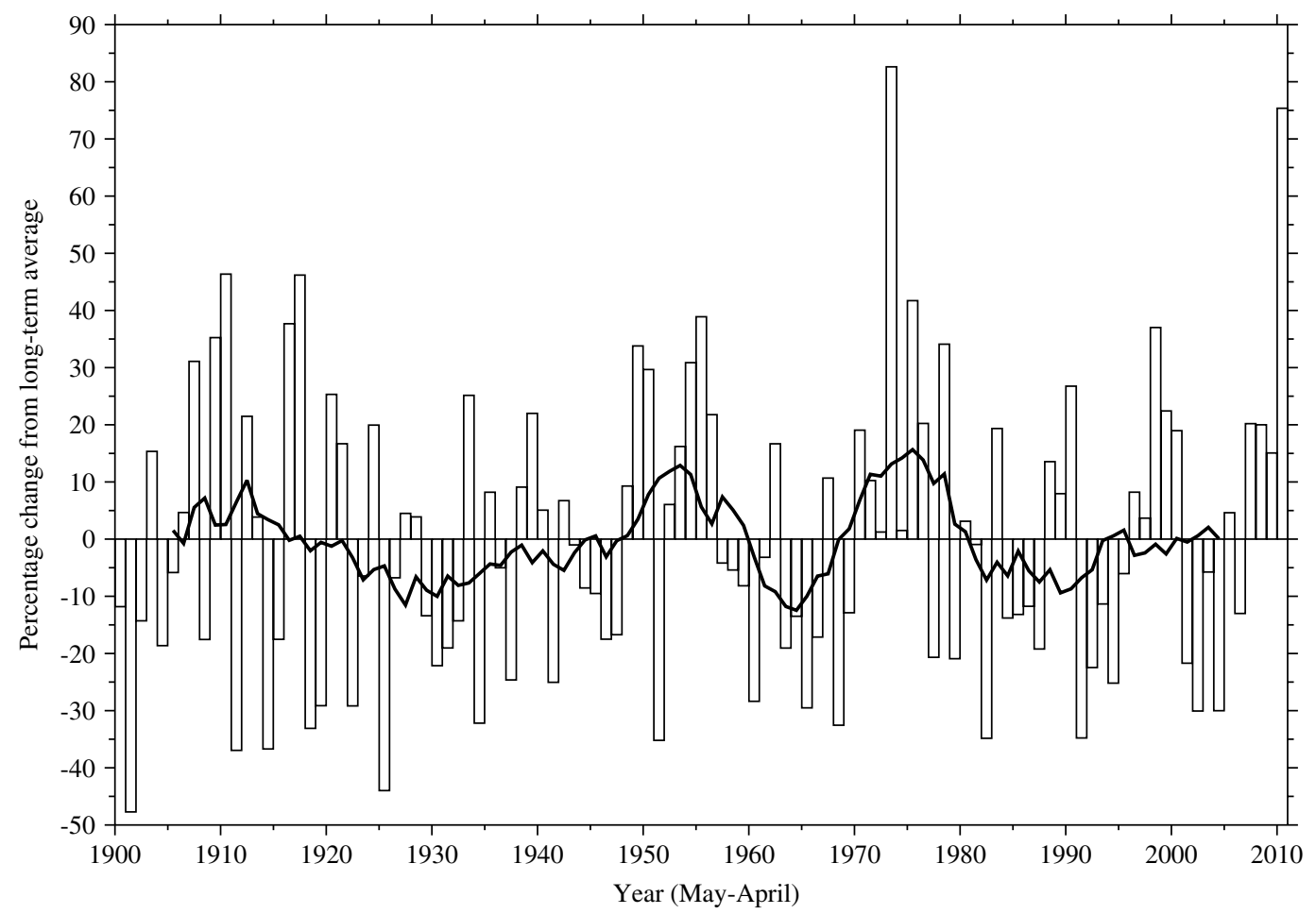

Figure 1. In unfilled bars, percentage anomalies of annual-mean (May-April) area-averaged rainfall across land points in a box approximating Queensland $\left(9^{\circ}-29^{\circ} \mathrm{N}, 138^{\circ}-154^{\circ} \mathrm{E}\right.$, using the SILO dataset of kriged station gauges, against the $1900-2010$ climatology. The thick black line shows the 11-year running mean of the unfilled bars.

2007) and the Inter-Decadal Pacific Oscillation (IPO; e.g. Power et al., 1999), and to a lesser extent to the Southern Annular Mode (SAM; e.g. Meneghini et al., 2007; Hendon et al., 2007). Local patterns of atmospheric variability also influence seasonal rainfall in Queensland, particularly variability in the extra-tropical storm tracks due to Southern Ocean blocking (Pook and Gibson, 1999; Risbey et al., 2009a) and intense coastal depressions (Holland, 1997), as well as tropical cyclones (TCs) (Lough, 1993; Walsh and Syktus, 2003; Flay and Nott, 2007). The current understanding of how these drivers influence Queensland is summarized in the following paragraphs.

During the warm, El Niño phase of ENSO, the zonally overturning atmospheric Walker Circulation shifts east, moving its ascending branch further away from Australia and the descending branch closer. El Niño is therefore associated with drought in Queensland (McBride and Nicholls, 1983; Allan, 1988; Lough, 1991). The opposite is true during La Niña: anomalous ascent over Australia and warmer local sea-surface temperatures (SSTs) promote above-average rainfall. Queensland is affected most strongly by ENSO events that are focused in the central Pacific, as represented by the Niño 4 SST index (Murphy and Ribbe, 2004; Wang and Hendon, 2007). The ENSO-Queensland rainfall teleconnection is strongest in spring and weakest in autumn, the latter due to weak and incoherent ENSO activity during the 'predictability barrier' (Webster and Yang, 1992).

Power et al. (2006), Cai et al. (2010) and others have shown that decadal and multi-decadal fluctuations in
Pacific SSTs, termed the IPO, influence the strength of the ENSO-rainfall teleconnection in Australia. Near the equator, the IPO resembles a prolonged, zonally stretched ENSO; SST anomalies in the sub-tropical and extra-tropical Pacific oppose the equatorial anomalies (Folland et al., 2002). It is unclear whether the IPO is physically distinct from the multi-decadal rectification of ENSO variability (Newman et al., 2003; Power et al., 2006). The positive IPO, with warm (cool) equatorial (extra-tropical) SST anomalies, is associated with a weak ENSO teleconnection in Australia and reduced interannual variability in ENSO and Australian rainfall (Cai et al., 2001; Arblaster et al., 2002); the negative IPO has the opposite impact.

The SAM is the dominant mode of Southern Hemisphere extra-tropical circulation variability (Rogers and van Loon, 1982; Gong and Wang, 1999; Thompson and Solomon, 2002). The positive SAM is associated with zonally symmetric positive (negative) mid-latitude (Antarctic) MSLP anomalies and a poleward shift in the Southern Ocean westerlies (Thompson and Wallace, 2000). These shifts in the mid-latitude storm track primarily influence rainfall in southern Australia (Hendon et al., 2007; Risbey et al., 2009b), although Meneghini et al. (2007) found that the positive (negative) SAM increased (decreased) winter and spring rainfall in southern Queensland via easterly (westerly) wind anomalies, increasing (reducing) onshore moisture transport.

Blocking anti-cyclones in the Southern Ocean also influence the mid-latitude storm track (Trenberth and Mo, 1985; Renwick and Revell, 1999; Pook and Gibson, 
1999). These circulation distortions steer many cyclones south of Australia, but also allow 'cut-off lows', closed areas of cyclonic circulation, to form north of the block (Qi et al., 1999; Pook et al., 2006). Cut-off lows often bring considerable rain to southern and central Australia, including southern Queensland, producing a positive correlation between blocking and seasonal precipitation (Risbey et al., 2009b). Southern Ocean blocking occurs most frequently in winter and spring (Lejenäs, 1984; Pook and Gibson, 1999). Blocks also form in the Tasman Sea between Australia and New Zealand, where, similar to the positive SAM, they enhance onshore moisture transport and coastal rainfall.

An average of four TCs year ${ }^{-1}$ form in the Coral Sea, most frequently in January-March; zero to three cyclones year ${ }^{-1}$ strike Queensland (Grant and Walsh, 2001; Walsh et al., 2004; Flay and Nott, 2007). Lough (1993) found significant positive correlations between the number of landfalling TCs and both Queensland annual rainfall and the frequency of daily accumulations exceeding $50 \mathrm{~mm}$. The number of landfalling TCs has declined since the late 1800s (Callaghan and Power, 2011); the cause of this remains unclear. El Niño (La Niña) is associated with an eastward (westward) shift in tropical cyclogenesis regions in the Southwest Pacific, reducing (increasing) the number of landfalling TCs in eastern Australia (Hastings, 1990; Kuleshov et al., 2009). Callaghan and Power (2011) demonstrated that all years with multiple TC landfalls were La Niña years, while Walsh and Syktus (2003) concluded that near the Queensland coast strong La Niña conditions were associated with five times as many TC days as strong El Niño conditions. Flay and Nott (2007) suggested that the IPO drives decadal variability in southwest Pacific TCs.

Recently, Risbey et al. (2009b) examined the relative roles of the ENSO, the SAM, the Indian Ocean Dipole (IOD; Saji et al., 1999) and Southern Ocean blocking on rainfall across Australia, using correlations with seasonal rainfall. The ENSO showed the greatest correlation in all seasons with rainfall in most regions of Queensland, although in southeastern Queensland blocking and the SAM dominated in spring.

The IOD is not considered as a potential driver of Queensland rainfall in this study. Previous research has concluded that the IOD does not cause rainfall variability in Queensland independent of ENSO (Nicholls, 1989; Murphy and Ribbe, 2004; Risbey et al., 2009b; Smith and Timbal, 2010). Although the IOD was initially included in this analysis, it was found to have no statistically significant impact on Queensland rainfall in any season.

\subsection{Motivation and objectives}

While many studies have examined point correlations between rainfall across Australia and individual drivers, few have attempted to link coherent spatial patterns of Australian rainfall variability to large-scale climate drivers. In this study, state-wide and regional patterns of seasonal rainfall variability will be associated with the potential drivers introduced in Section 1.2. The patterns will be determined by applying empirical orthogonal teleconnection (EOT; Van Den Dool et al., 2000) decomposition (Section 2.2) to the SILO kriged gauge rainfall analysis for 1900-2010 (Section 2.1). Compared to standard correlation analysis, the EOT technique has the advantage of identifying distinct, independent regional patterns of rainfall variability, which can then be associated with particular driving mechanisms (e.g. changes in circulation patterns, variations in cyclone activity). These associations will be formed by regressing the EOT timeseries onto observations and reanalysis data. Section 3 introduces the EOT patterns and analyses their temporal variability; the associations between each EOT and its atmospheric drivers are discussed in Section 4. The authors discuss and summarize the key conclusions of this study in Section 5.

\section{Datasets and methods}

\subsection{SILO rainfall analysis}

Monthly and seasonal rainfall totals were taken from the SILO dataset of kriged gauge values on a $25 \mathrm{~km}$ grid (Jeffrey, 2001). SILO data were available for 1890-2010; the March 1900-February 2010 period (hereafter 1900-2010) is analysed, as very few Queensland stations have records before 1900 (Lough, 1991; Lavery et al., 1997). This provides 112 years of data for each season: December-February (DJF), March-May (MAM), June-August (JJA) and September-November (SON). Jeffrey (2001) used cross-validation to show that the monthly SILO totals were reliable across most of Queensland, with relatively higher (lower) skill in coastal regions (the Cape York peninsula) where station densities are high (low).

\subsection{EOT analysis}

First described by Van Den Dool et al. (2000), EOT analysis decomposes a temporally and spatially varying field into a set of orthogonal patterns (EOTs). Unlike empirical orthogonal function (EOF) analysis, which produces patterns that are orthogonal in space and time, EOTs are orthogonal in either space or time; this study employs the latter. In the Van Den Dool et al. (2000) method, decomposition is achieved by first identifying the spatial point within the search domain that explains the greatest temporal variance at all other points. This is the 'central point' of the leading EOT; its timeseries becomes the timeseries of the leading EOT. The effect of the central point on all other points is then removed by linear regression, before identifying the point at which the residual timeseries explains the most variance in the residual field. This point becomes the central point of the second EOT. The technique is repeated until the desired number of patterns are found. Van Den Dool et al. (2000) demonstrated that EOTs of commonly used climate fields 
Table I. For the three leading EOTs of seasonal Queensland rainfall: the percentage of variance in the area-averaged, seasonal Queensland rainfall explained; the correlations between the EOT timeseries and Niño 4, the Inter-decadal Pacific Oscillation index, the Bureau of Meteorology blocking index longitude-averaged over $120-150{ }^{\circ} \mathrm{E}\left(\mathrm{B}_{120-150}\right)$ and $150-180^{\circ} \mathrm{E}\left(\mathrm{B}_{150-180}\right)$ and the SAM index. For the SAM, partial correlations with EOT timeseries are also computed, removing the influence of Niño 4; these are denoted by $\left.\mathrm{SAM}\right|_{\mathrm{N} 4} . \mathrm{A}^{*}(* *)$ indicates correlations that are statistically significant at the 5\% (1\%) level.

\begin{tabular}{|c|c|c|c|c|c|c|c|}
\hline EOT & Var. expl. & Niño 4 & IPO & $\mathrm{B}_{120-150}$ & $\mathrm{~B}_{150-180}$ & SAM & $\left.\mathrm{SAM}\right|_{\mathrm{N} 4}$ \\
\hline \multicolumn{8}{|l|}{$D J F$} \\
\hline EOT 1 & $37.71 \%$ & $-0.35^{* *}$ & $-0.44^{* *}$ & -0.04 & 0.03 & 0.28 & 0.24 \\
\hline EOT 2 & $8.63 \%$ & -0.20 & -0.02 & -0.04 & -0.10 & 0.15 & 0.12 \\
\hline EOT 3 & $7.36 \%$ & -0.18 & -0.22 & $0.24^{*}$ & 0.12 & 0.05 & 0.00 \\
\hline \multicolumn{8}{|l|}{$M A M$} \\
\hline EOT 1 & $32.17 \%$ & -0.17 & -0.19 & -0.02 & -0.16 & 0.09 & 0.09 \\
\hline EOT 2 & $13.54 \%$ & -0.06 & 0.01 & 0.21 & -0.15 & -0.05 & -0.04 \\
\hline EOT 3 & $8.64 \%$ & $-0.39^{* *}$ & $-0.36^{* *}$ & 0.05 & 0.18 & 0.16 & 0.15 \\
\hline \multicolumn{8}{|l|}{$J J A$} \\
\hline EOT 1 & $45.12 \%$ & $-0.37^{* *}$ & $-0.29 *$ & 0.23 & 0.00 & 0.25 & $0.38^{*}$ \\
\hline EOT 2 & $9.85 \%$ & -0.13 & -0.11 & -0.10 & $0.26^{*}$ & 0.08 & 0.11 \\
\hline EOT 3 & $6.63 \%$ & -0.04 & -0.08 & 0.11 & 0.19 & $-0.32^{*}$ & $-0.30^{*}$ \\
\hline \multicolumn{8}{|l|}{ SON } \\
\hline EOT 1 & $41.34 \%$ & $-0.44^{* *}$ & $-0.39^{* *}$ & 0.18 & $0.29^{*}$ & $0.34^{*}$ & $0.32^{*}$ \\
\hline EOT 2 & $10.91 \%$ & $-0.30^{*}$ & $-0.25^{*}$ & 0.09 & 0.12 & 0.00 & -0.06 \\
\hline EOT 3 & $6.80 \%$ & -0.12 & -0.04 & $0.26^{*}$ & 0.12 & $0.31^{*}$ & $0.30^{*}$ \\
\hline
\end{tabular}

strongly resembled rotated EOFs, but the EOTs were computed much more efficiently.

Smith (2004) argued for a modified EOT procedure for Australia, in which patterns are identified by the explained variance in the domain area-averaged rainfall, rather than by the sum of the explained space-time variance over all points. Since most of the rain in Australia, and hence nearly all of the variance, is concentrated along the coast, Smith (2004) found that the temporal variance in the spatially averaged rainfall was a less-biased descriptor than the space-time variance. Using the latter would result in EOT patterns heavily shifted toward the coast. Rotstayn et al. (2010) applied the Smith (2004) procedure to analyse improvements in the CSIRO Mk3.6 model's simulation of inter-annual Australian rainfall variability.

Here, EOTs are computed using the Smith (2004) method for each season using seasonal-total 1900-2010 SILO rainfall over a domain approximating Queensland: $9-30^{\circ} \mathrm{S}, 138-154^{\circ} \mathrm{E}$. The first three EOTs are analysed for each season, as together these patterns explain at least $53 \%$ of the variance in the Queensland-average rainfall timeseries (Table I). Subsequent EOTs each explain less than $5 \%$ of the variance. The EOT patterns are presented in Section 3.

\subsection{Atmospheric and SST data}

To analyse links to the atmospheric circulation, each EOT timeseries was linearly regressed against fields from the 20th Century Reanalysis (20CR; Compo et al., 2011) for 1900-2010. The 20CR differs from other reanalyses [e.g. the European Centre for Medium-Range Weather Forecasting 40-year reanalysis (ERA40; Uppala et al., $2005)$ ] in that (1) it is constrained only by observations of surface pressure, SST and sea ice, and (2) it employs an Ensemble Kalman Filter data-assimilation technique to create an ensemble reanalysis with 56 members. The ensemble-mean 20CR fields are used here, except where otherwise noted, as the ensemble mean represents the most likely state of the atmosphere (Compo et al., 2011). The longer period of the 20CR compared to other reanalyses allows better resolution of the decadally and multi-decadally varying signals that are critical components of the variability in Queensland rainfall.

All 1900-2010 20CR regressions shown in this study were also computed for the ERA-40 period (1958-2001) and compared to regressions using ERA-40 data. The 20CR regressions were qualitatively similar to their ERA40 counterparts, so the 1900-2010 20CR regressions are used throughout. The $20 \mathrm{CR}$ is less reliable in the early 20th century, as there are few available Southern Hemisphere surface-pressure observations to constrain the model.

Seasonal-mean MSLP, 850 and $500 \mathrm{hPa}$ winds and $500 \mathrm{hPa}$ specific humidity on a $2^{\circ}$ longitude $\times 2^{\circ}$ latitude grid were taken from the 20CR for 1900-2010. The climatological, seasonal-mean 850 and $500 \mathrm{hPa}$ winds are shown in Figure 2 to aid interpretation of the anomalous circulations from the regression analysis. Key features include the DJF monsoon cyclone near $10^{\circ} \mathrm{S}$ (Figure 2(a)), strong onshore winds along the Queensland coast in DJF and MAM (Figure 2(c)), and the northward shift of the mid-tropospheric subtropical jet in JJA (Figure 2(f)).

Additionally, timeseries of the seasonal standard deviation in 2- to 10-d bandpass-filtered MSLP (MSLP $\left.{ }_{2-10 d}\right)$ were constructed to diagnose seasonal-timescale variations in synoptic activity. This quantity does not reflect 

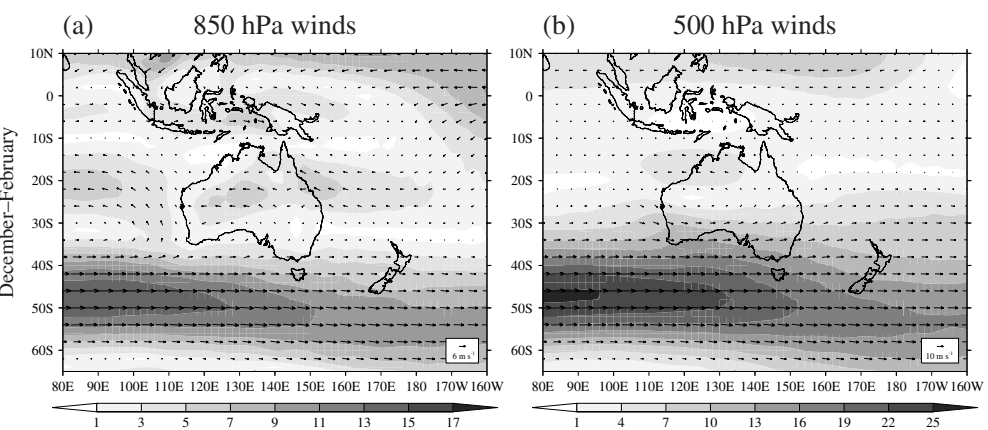

(c)
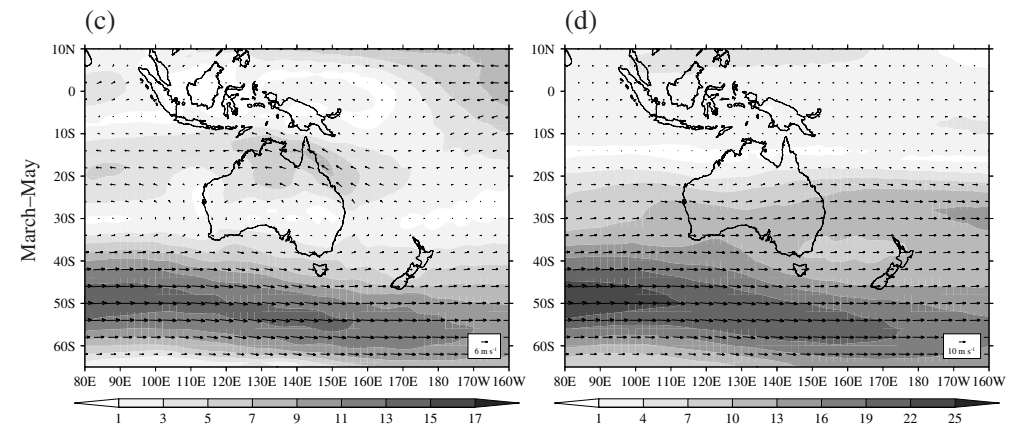

(e)
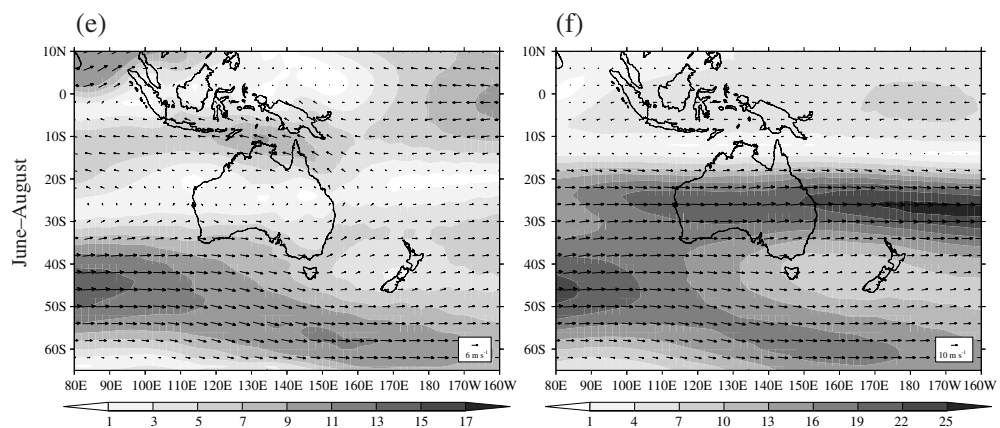

(g)

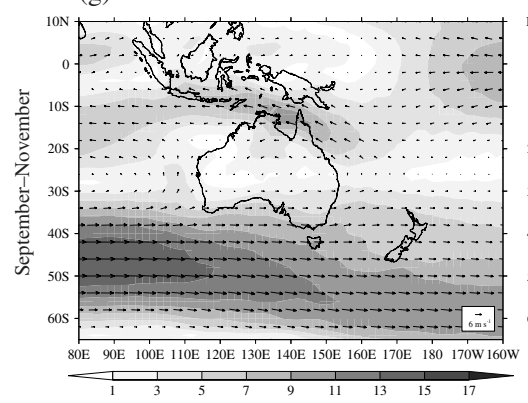

(h)

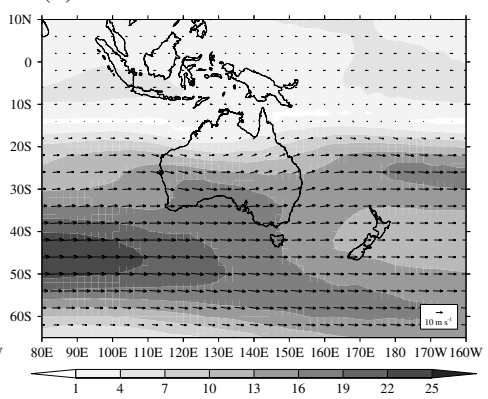

Figure 2. Seasonal-mean (left) $850 \mathrm{hPa}$ and (right) $500 \mathrm{hPa}$ winds from the 20th Century Reanalysis for (a, b) December-February, (c, d) March-May, (e, f) June-August and $(\mathrm{g}, \mathrm{h})$ September-November. The vectors show the wind direction and magnitude (using the key vector at bottom right); the filled contours give the wind magnitude.

the tracks of individual weather systems; it represents the aggregated locations of those systems across the entire season. For this diagnostic, the bandpass filtering was applied to each of the 56 ensemble members individually. The seasonal standard deviation at each gridpoint was computed for each ensemble member, then averaged across the ensemble. Rainfall regressions are computed using this ensemble-mean standard deviation field.

Seasonal-mean 1900-2010 SSTs from the $1^{\circ} \times 1^{\circ}$ Hadley Centre sea Ice and SST dataset (HadISST; Rayner et al., 2003) are used to identify SST patterns linked to each EOT. Monthly indices of Niño 3, Niño 3.4 and
Niño 4 SSTs are taken from HadISST. The IPO index is that of Parker et al. (2007): HadISST SSTs projected onto the leading EOF of 13-year lowpass-filtered HadSST2 SSTs (Rayner et al., 2006).

Tropical-cyclone tracks for the South Pacific basin were obtained from the International Best Track Archive for Climate Stewardship (IBTrACS; Knapp et al., 2010). Due to limited observational coverage in the basin prior to the satellite era, cyclone tracks were analysed for 1979-2010 only.

Links between rainfall EOTs and blocking are computed using the Bureau of Meteorology blocking index 
(Pook and Gibson, 1999) from the 20CR. The index identifies splits in the mid-tropospheric jet, which are associated with blocking anti-cyclones. At every longitude, the index $B$ is defined as

$$
B=0.5\left(U_{25}+U_{30}-U_{40}-2 U_{45}-U_{50}+U_{55}+U_{60}\right)
$$

where $U_{x}$ is the monthly-mean $500 \mathrm{hPa}$ zonal wind from 20CR at latitude $x$. Seasonal means of $B$ were computed from monthly values, then longitude-averaged over two bands in the Southern Ocean $-120^{\circ}-150^{\circ} \mathrm{E}\left(\mathrm{B}_{120-150}\right)$ and $150^{\circ} \mathrm{E}-180^{\circ}\left(\mathrm{B}_{150-180}\right)$ - where blocking activity is known to influence Australian rainfall (Qi et al., 1999; Pook et al., 2006; Risbey et al., 2009a, 2009b).

For correlations between rainfall EOTs and the SAM, we use the station-pressure SAM index of Marshall (2003), computed as the difference between normalized monthly-mean, zonal-mean sea-level pressures at $40^{\circ} \mathrm{S}$ minus those at $65^{\circ} \mathrm{S}$ (Gong and Wang, 1999). Seasonal means of the SAM index were obtained for 1958-2010.

\section{EOT patterns}

Correlation maps for the three EOTs for each season that explain the most variance in area-averaged Queensland rainfall are shown in Figure 3. An inverted triangle identifies the central point; the values displayed are the statistically significant (at the 5\% level) correlations of the rainfall timeseries (for EOT 1) or residual rainfall timeseries (for EOTs 2 and 3 ) at each gridpoint with that at the central point. In each season, the leading EOT explains by far the greatest percentage of the variance in the area-averaged Queensland rainfall (Table I) and has uni-polar correlations across Queensland (Figure 3, left column). The locations of the EOT 1 central points and the regions of highest positive correlations follow the climatological seasonal cycle of rainfall: in the tropical north during the summer monsoon, and in the sub-tropical south in winter due to the influence of mid-latitude weather systems. The largest fraction of the inter-annual variability in Queensland's rainfall occurs via the EOT 1 state-wide rainfall anomalies and displays little regional variation.

Once the leading, state-wide patterns are removed, the remaining EOTs identify regions of Queensland that vary coherently and that occasionally oppose variations in other regions. Rainfall variations in the Cape York Peninsula are disconnected from the remainder of the state during the wet half-year in summer (DJF EOT 2; Figure 3(b)) and autumn (MAM EOT 3; Figure 3(f)). These EOTs each explain more of the variance in total Cape York rainfall than do the corresponding leading, state-wide EOTs (DJF EOT 1 and MAM EOT 1, respectively). Southeastern Queensland is another region of coherent variation, especially in winter (JJA EOT 2; Figure 3(h)) and spring (SON EOT 3; Figure 3(1)). The former EOT also demonstrates that winter rainfall anomalies in the southeast and the west are anti-correlated.
EOTs 2 and 3 suggest separations of rainfall variability between the tropical north and the subtropical southeast, as well as between coastal and inland regions.

The state-wide EOT 1 timeseries have trends and variability similar to Lough (1997) for all-Queensland rainfall: summer rainfall has declined since the mid1970s (Figure 4(a)), potentially as part of a multi-decadal oscillation, while winter rainfall shows local minima in the 1920s and 1990s (Figure 4(g)). The southeast has experienced additional drying in recent decades in winter (JJA EOT 2; Figure 4(h)) and summer (DJF EOT 3; Figure 4(c)), which agrees with trends at coastal stations in Queensland and New South Wales (Gallant et al., 2007; Speer et al., 2011). There are no statistically significant linear trends in any EOT over 1900-2010 (not shown), consistent with Nicholls and Lavery (1992) and Lough (1997).

The timeseries of four EOTs display substantial levels of decadal and multi-decadal variability: DJF EOTs 1 and 3, MAM EOT 2 and JJA EOT 2 (Figure. 4(a),(c),(e) and (h)). The latter three of these are centred in southeastern Queensland. Wavelet transforms with a Morlet mother wavelet (Torrence and Compo, 1998) confirmed that these EOTs showed statistically significant power at the 10- to 30-year periods across the 1900-2010 period (not shown). No other EOT has temporally consistent, statistically significant power at any single period, suggesting that southern Queensland experiences more decadal and multi-decadal rainfall variability than the remainder of the state. Section 4.1 will show that DJF EOT 1 is driven by the ENSO and the IPO, while Section 4.4 will demonstrate that the other three EOTs are associated with local synoptic variability. The latter finding is significant, as it suggests that the weather patterns influencing southern Queensland have natural decadal and multi-decadal variability that is independent of external forcing from large-scale climate drivers such as ENSO. The three southern Queensland EOTs also show significant interannual variability during 1950-1980, which was also confirmed by the wavelet transform. This is consistent with Speer (2008), which concluded that the 1948-1975 negative IPO phase led to increased inter-annual variability in coastal eastern Australian rainfall.

\section{Associations of EOTs with large-scale drivers}

Linear correlation and regression analysis is employed to determine any associations between the EOTs and potential drivers: the ENSO and the IPO (Section 4.1), tropical-cyclone activity (Section 4.2), local circulation patterns (e.g. blocking) and extra-tropical cyclone activity (Section 4.4). Some of the EOTs linked to ENSO also show links with the SAM (Section 4.1). Table I gives the correlations of each EOT and the indices for these drivers (Section 2). All regression coefficients shown in Figures 5-12 are scaled to describe a change in the regressed field (e.g. MSLP, $850 \mathrm{hPa}$ winds) for a one standard deviation increase in the EOT. 

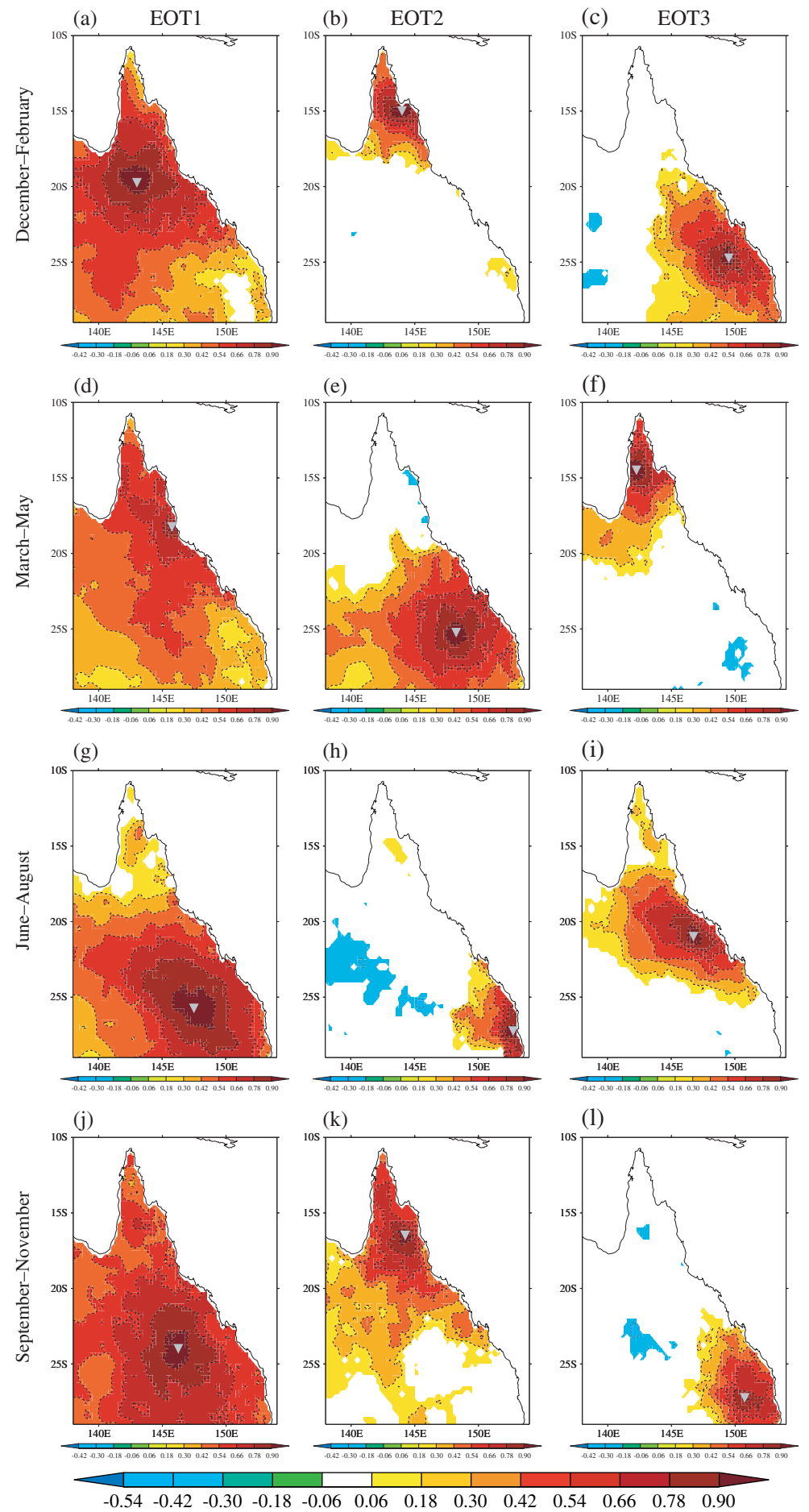

Figure 3. Correlations of the timeseries of seasonal-total (for EOT 1) or residual seasonal-total (EOTs 2 and 3) rainfall at each point with the EOT base point, which is marked with an oversized inverted triangle. The base point is the one that explains the greatest variance in the area-average (EOT 1) or the residual area-average (EOTs 2 and 3) Queensland rainfall once any preceding EOTs have been removed by linear regression. Correlations are shown only where statistically significant at the 5\% level. This figure is available in colour online at wileyonlinelibrary.com/journal/joc

\subsection{EOTs driven by ENSO and the IPO}

Five EOTs - DJF EOT 1, MAM EOT 3, JJA EOT 1 and SON EOTs 1 and 2 - show statistically significant correlations with Niño 4 and the IPO at the 5\% level or above (Table I). Regressions of HadISST SSTs on each EOT timeseries confirm the relationships between variability in rainfall and equatorial Pacific SSTs (Figure 5(a)-(e)).
Lag regressions of monthly Niño 4 anomalies against each EOT demonstrate that DJF EOT 1 is related to ENSO events that peak concurrently; the JJA and SON EOT 1 patterns are related to ENSO events that peak in the following DJF; and MAM EOT 3 is related to the ENSO of the preceding DJF (Figure 6). The lag regressions for SON EOT 2 are discussed later in this section. 

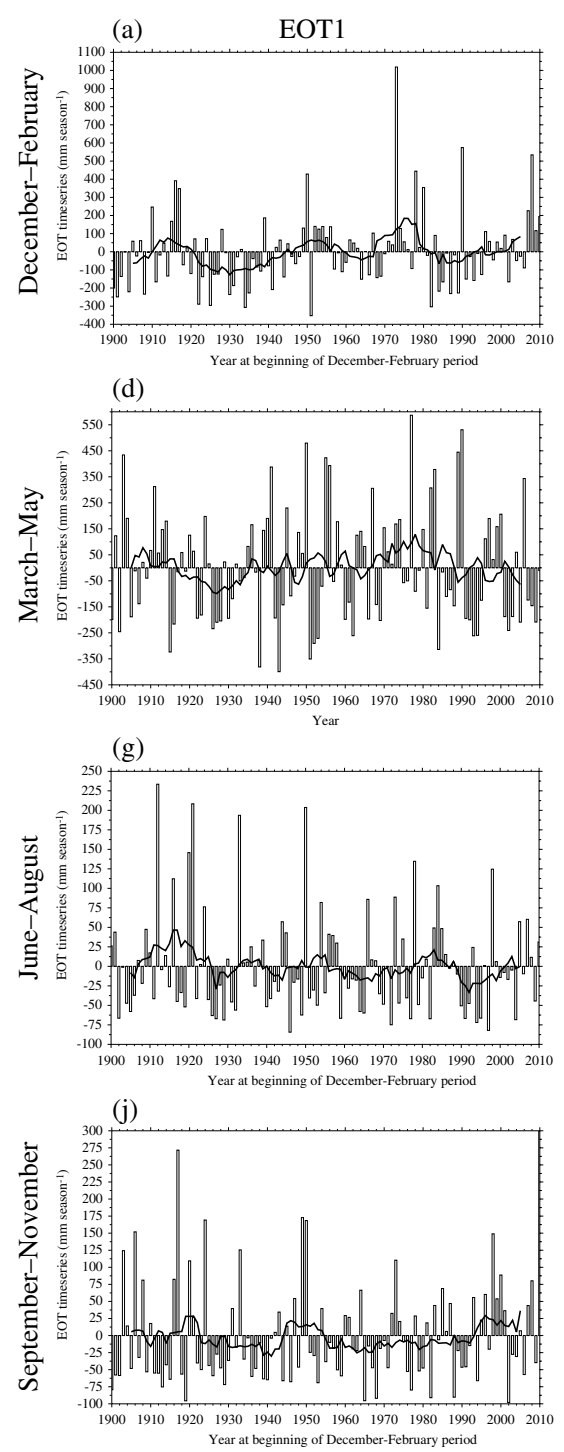

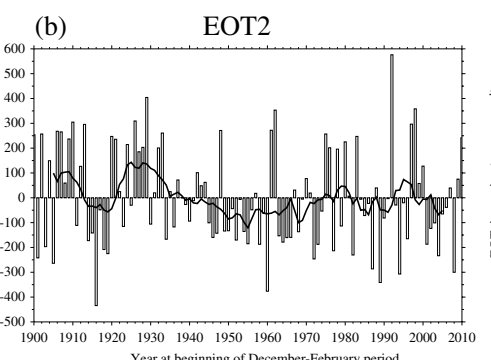

(e)

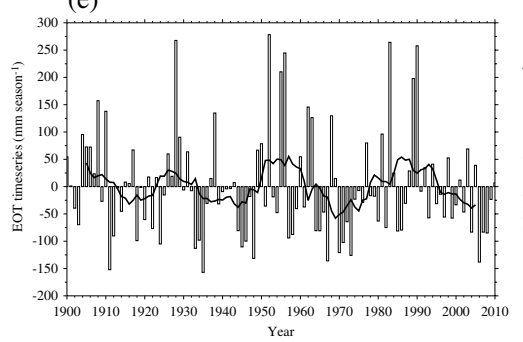

(h)

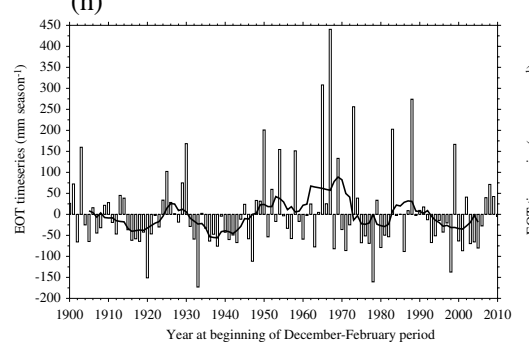

(k)

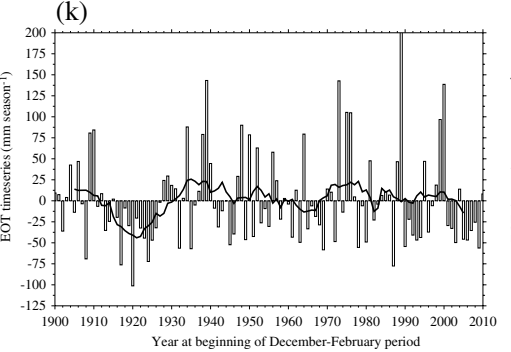

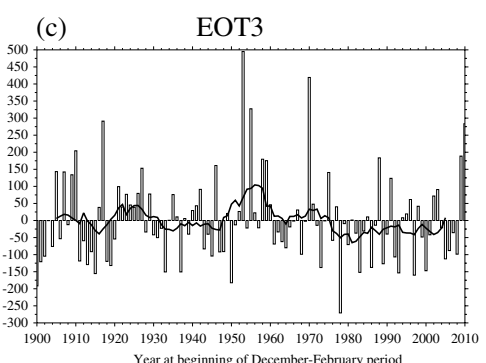

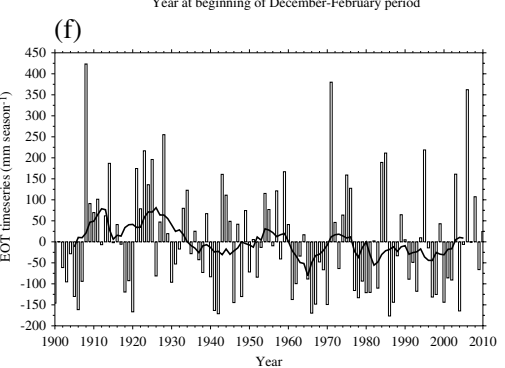

(i)
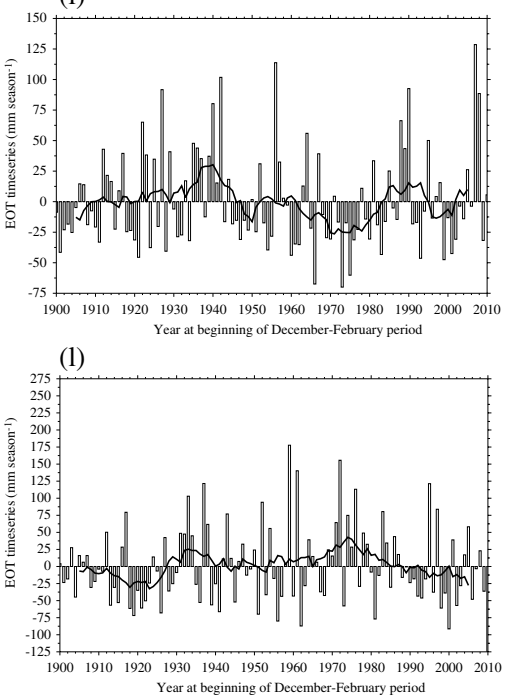

Figure 4. Annual timeseries (unfilled bars, mm season ${ }^{-1}$ ) and their 11-year running means (thick lines) for (a) DJF EOT 1, (b) JJA EOT 1, (c) JJA EOT 2 and (d) DJF EOT 3. The timeseries are expressed as anomalies from their mean for ease of interpretation.

During the austral monsoon, state-wide rainfall anomalies are associated with equatorial and off-equatorial Pacific SST variability (Figure 5(a)). The spatial pattern of SST regression coefficients strongly resembles the negative (cool) IPO (Power et al., 1999). Indeed, DJF EOT 1 is more strongly correlated with the IPO than with Niño 4, although both are statistically significant at $1 \%$ (Table I). Combined with the statistically significant multi-decadal power in DJF EOT 1 (Section 3), this argues that multi-decadal Pacific SST variability exerts a control on inter-annual and multi-decadal fluctuations in summer rainfall.

Windowed correlations were computed between DJF EOT 1 and Niño 4 for 1900-2010, using 11-, 31- and 51year windows (not shown). The 11-year windowed correlation displays considerable decadal variation in sign and magnitude. The timeseries of the windowed correlation was itself positively correlated $(r=+0.42$, significant at $5 \%$ ) with an 11-year running mean of the IPO index, such that decades of a weak (strong) correlation between
DJF EOT 1 and Niño 4 occurred during IPO warm (cool) phases. The 31- and 51-year windowed correlations were stable and statistically significant throughout the period.

Years of positive DJF EOT 1 are associated with an intensified $850 \mathrm{hPa}$ cyclonic monsoon circulation over much of Australia, as well as anomalous convergence over the Maritime Continent that reflects a westward shift in the Walker Circulation (Figure 5(f)). The positive SOI can also clearly be seen, reinforcing the association with the ENSO. Thus, DJF EOT 1 represents variations in the summer monsoon that are linked to the dominant modes of inter-annual and inter-decadal Pacific climate variability and the interactions between them.

In autumn, the ENSO transition season, Niño 4 and the IPO are correlated only with EOT 3 (Table I), centred in northern Queensland. This is consistent with Risbey et al. (2009b) and others, who found that MAM showed the weakest teleconnection between ENSO and eastern Australian rainfall of all seasons. SST regressions are weaker than for DJF EOT 1; in the extra-tropics, only small 
(a) DJF EOT1

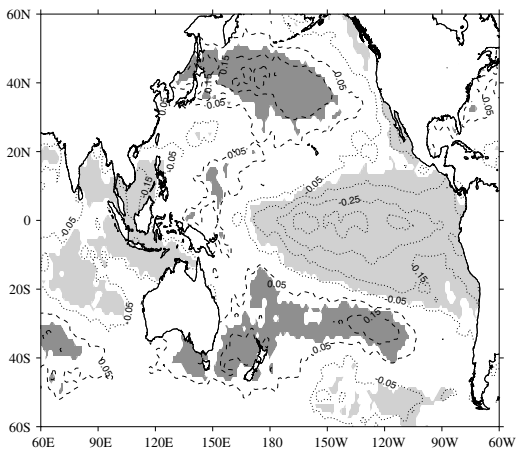

(b) MAM EOT3

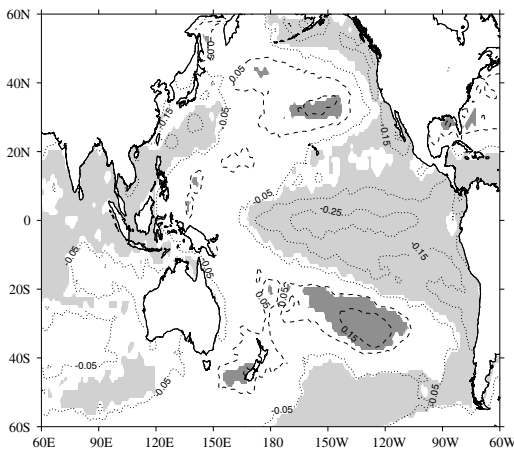

(c) JJA EOT1

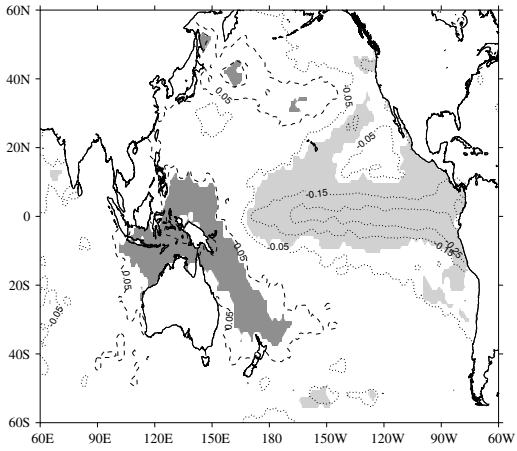

(d) SON EOT1

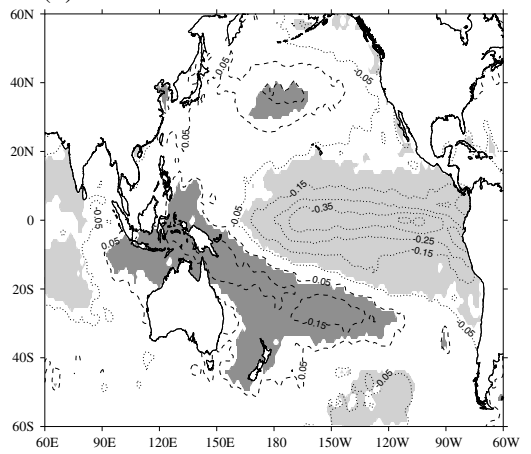

(e) SON EOT2

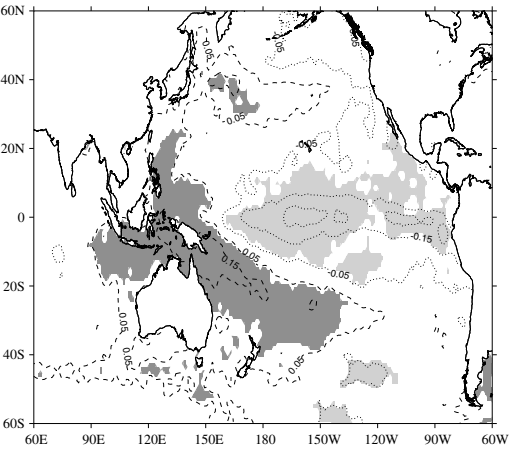

(f) DJF EOT1

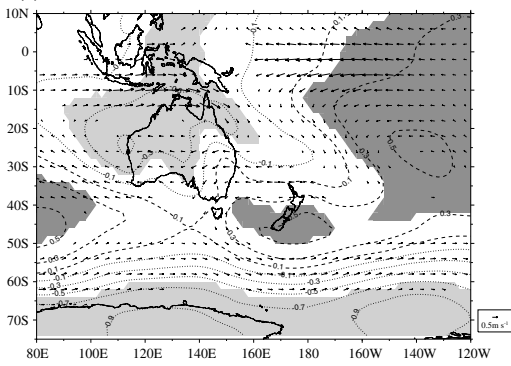

(i) SON EOT1

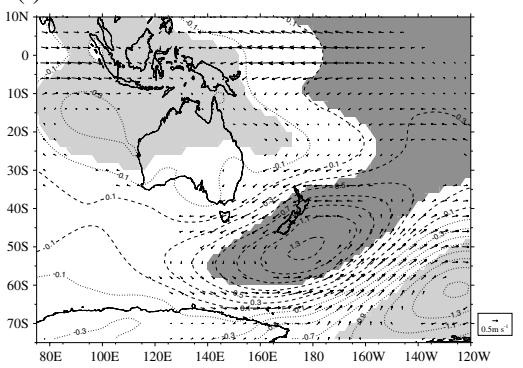

(g) MAM EOT3

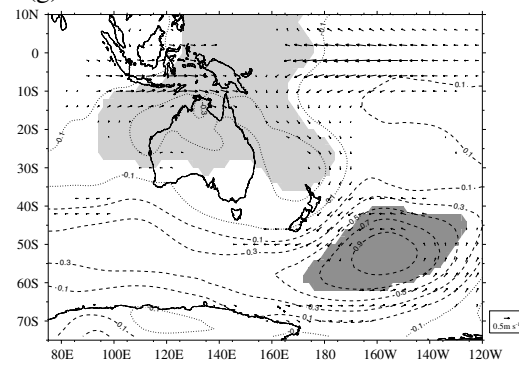

(h) JJA EOT1

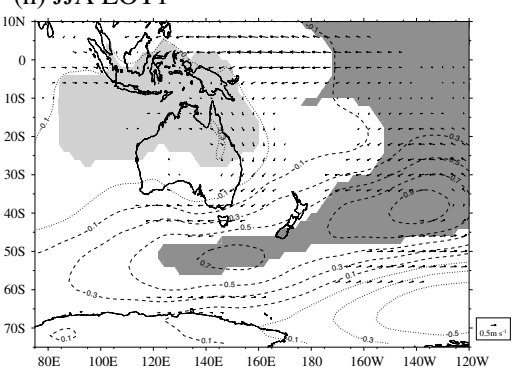

(j) SON EOT2

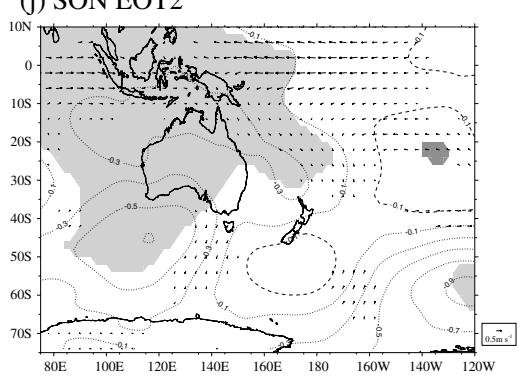

Figure 5. For (a, f) DJF EOT 1, (b, g) MAM EOT 3, (c, h) JJA EOT 1, (d, i) SON EOT 1 and (e, j) SON EOT 2, (a-e) regression coefficients for HadISST SSTs on EOT timeseries, and (f-j) regression coefficients for (contours and shading) MSLP and (vectors) $850 \mathrm{hPa}$ winds on EOT timeseries. The contour interval is $0.1^{\circ}$ from $\pm 0.05^{\circ}$ for SST and $0.2 \mathrm{hPa}$ from $\pm 0.1 \mathrm{hPa}$ for MSLP; positive (negative) contours are dashed (dotted). Regression coefficients for SST and MSLP are shaded where significant at 5\%, using dark (light) grey shading for positive (negative) values; $850 \mathrm{hPa}$ winds are shown only where significant at $5 \%$.

regions show significant correlations (Figure 5(b)). The 11-year windowed correlation between Niño 4 and MAM EOT 3 shows decadal variability, but it is anti-correlated with the 11-year running mean of the IPO $(r=-0.32$, significant at $10 \%$ ), in contrast to the positive correlation for DJF EOT 1. There is no significant decadal variability in the MAM EOT 3 timeseries (Figure 4(f)), which with the limited off-equatorial Pacific SST signal suggests a weaker role for the IPO in autumn than summer. The anomalous circulation for MAM EOT 3 (Figure 5(g)) resembles the enhanced monsoon in DJF EOT 1, but with statistically significant wind anomalies over only northern Australia. This pattern likely represents the ENSO influence on the retreating monsoon, with La Niña (El Niño) promoting wet (dry) conditions across northern Queensland. 

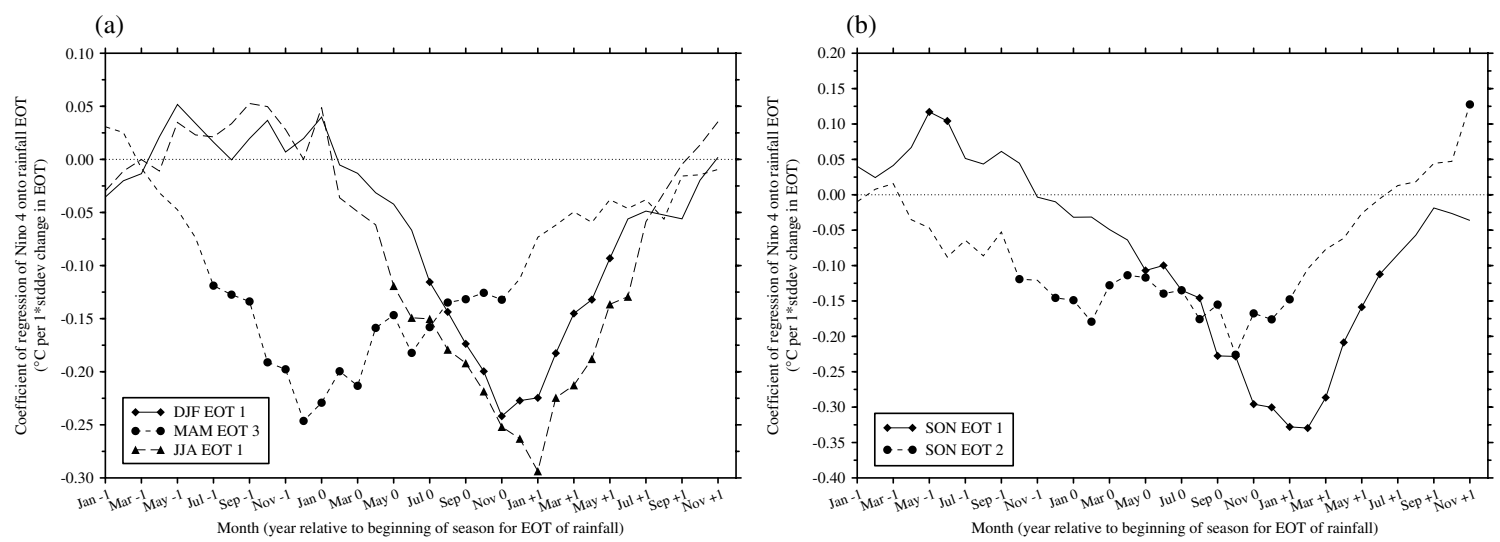

Figure 6. Coefficients of lagged regressions for the monthly-mean Niño 4 SST index onto (a) DJF EOT 1, MAM EOT 3 and JJA EOT 1; (b) SON EOTs 1 and 2, expressed as ${ }^{\circ} \mathrm{C}$ per one standard deviation increase in the EOT timeseries. The horizontal axis gives the month of the Niño 4 index, with the year $(-1,0$ or +1$)$ relative to the start of the season for the EOT timeseries (e.g. 'December 0 ' is the December of the same year as the EOTs). Symbols on the lines indicate coefficients that are statistically significant at $5 \%$. Note that (a) and (b) have different vertical axes.

Equatorial Pacific SST variability is also associated with the leading EOTs for winter (Figure 5(c)) and spring (Figure 5(d)). La Niña (El Niño) promotes warm (cold) SST anomalies near Queensland and anomalously low (high) pressure over northern Australia (Figure 5(h) and (i)). In winter, there is an anomalous northwesterly flow at $850 \mathrm{hPa}$ over Queensland (Figure 5(h)) that is associated with increased moisture transport from the tropics to northern Australia (not shown). There are no statistically significant circulation anomalies over Queensland for SON EOT 1, but the strong anti-cyclonic anomalies near New Zealand, combined with the significant correlation with $\mathrm{B}_{150-180}$ (Table I), may be evidence of blocking activity, which Risbey et al. (2009b) found produced increased rainfall in SON across southern Queensland. The 11-year windowed correlations of the winter and spring EOT 1 with Niño 4 show occasional decadal fluctuations, but are generally strong and statistically significant (not shown). The JJA 11-year windowed correlation between EOT 1 and Niño 4 is not significantly correlated with the 11-year IPO running mean, while the correlation for SON EOT 1 is similar to that for DJF EOT $1(r=+0.41$, significant at $5 \%)$.

In addition to their associations with the ENSO, the leading EOTs for winter and spring also show significant correlations with the SAM (Table I). The correlation remains significant when the partial correlations with Niño 4 - removing the linear influence of Niño 4 SSTs on the SAM and on each EOT - are computed. JJA EOT 1 and SON EOT 1 are associated with high (low) pressure anomalies across the $40^{\circ} \mathrm{S}\left(65^{\circ} \mathrm{S}\right)$ latitude belt (Figure 7(a) and (b)), along with strong easterlies (westerlies) at the same latitude (Figure 5(h) and (i)). This is consistent with a poleward shift in the westerlies and the positive SAM. As measured by the seasonal standard deviation in $\mathrm{MSLP}_{2-10 \mathrm{~d}}$, synoptic activity increases across southern Australia in positive EOT 1 seasons for JJA and SON (Figure 7(d) and (e)), suggesting that more cyclones track between $20-40^{\circ} \mathrm{S}$ at Australian longitudes. SON EOT 1 is positively correlated with $B_{150-180}$
(Table I), which may drive the formation of cut-off lows that track north of the block (Risbey et al., 2009b).

From this analysis, it is not possible to determine what portion of state-wide rainfall variability in JJA and SON is driven by ENSO and what portion by the SAM, only that both are correlated with the EOT 1 patterns. The MSLP anomalies in Figure 7(a) and (b) resemble the Southern Hemisphere extra-tropical wavetrain response to La Niña (Karoly, 1989; Mo, 2000), but also project strongly onto the SAM. The low-level circulation anomalies suggest a role for convergence near the Maritime Continent and the advection of tropical moisture, while the $\mathrm{MSLP}_{2-10 \mathrm{~d}}$ diagnostic implicates a stronger extra-tropical storm track. This suggests that in addition to the tropical circulation response to ENSO, extra-tropical variability associated with ENSO and the SAM is important for state-wide winter and spring rainfall.

While winter, summer and autumn each have only one EOT with a significant relationship with ENSO, spring has two: SON EOT 2 is also correlated with Niño 4 at $5 \%$ (Table I). SON EOT 2 is associated with weaker Pacific SST anomalies (Figure 5(e)) than is EOT 1 (Figure 5(d)). The correlation has been statistically significant only since 1960 (not shown), suggesting a stronger relationship between northern Queensland spring rainfall and ENSO during this period. Wet SON EOT 2 seasons show anomalous $850 \mathrm{hPa}$ convergence near the Maritime Continent and lower MSLP over northern Australia (Figure 5(j)), as for EOT 1, but lack the anti-cyclonic anomalies near New Zealand. Lagged regressions of monthly Niño indices against SON EOTs 1 and 2 demonstrate that while SON EOT 1 is associated with ENSO events that peak in the subsequent DJF, the ENSO events linked to SON EOT 2 decay in DJF (Figure 6(b)). Thus, strong, developing ENSO events in SON lead to Queensland-wide rainfall variations, while weaker, terminating ENSO events produce rainfall anomalies only in tropical northern Queensland. 
(a)

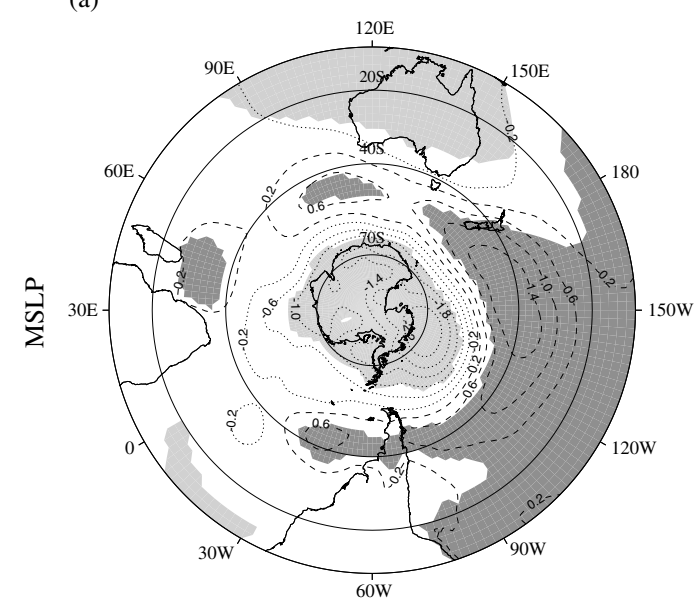

(c)

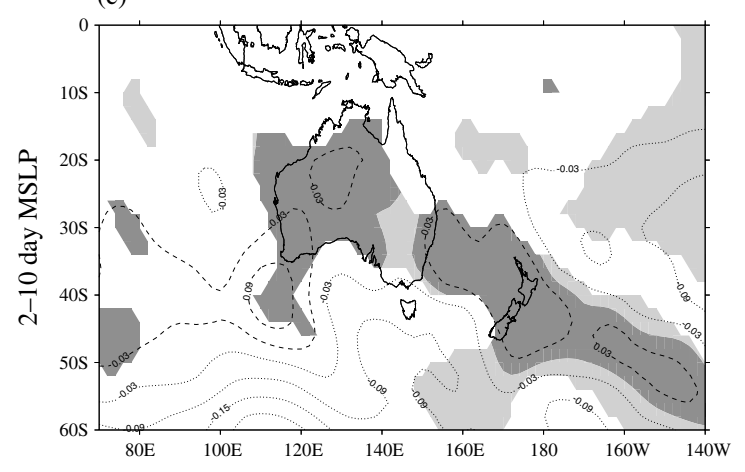

SON EOT1

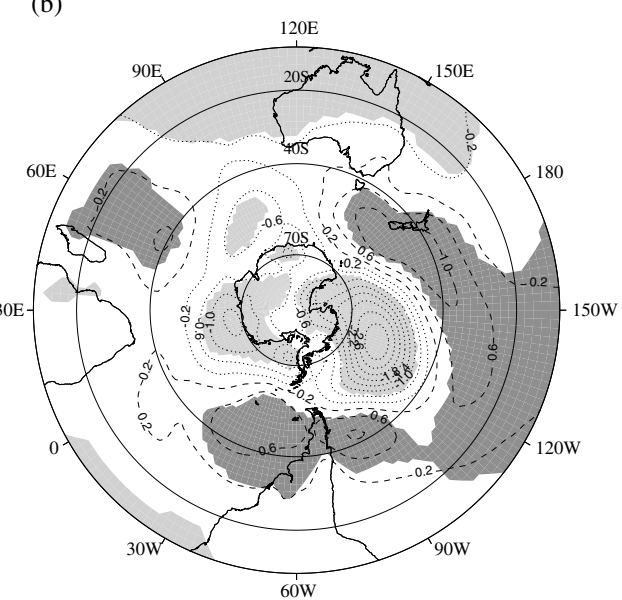

(d)

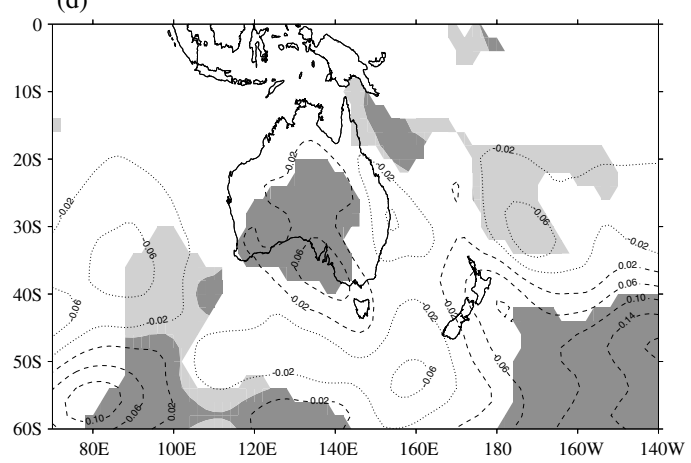

Figure 7. For (a, c) JJA EOT 1 and (b, d) SON EOT 1, the linear regression coefficients of (a, b) seasonal-mean MSLP and (c, d) the seasonal standard deviation of $\mathrm{MSLP}_{2-10 \mathrm{~d}}$ onto the EOT timeseries. The data period is $1958-2007$, for consistency with the SAM dataset. The contour interval is (left) $0.4 \mathrm{hPa}$ from $\pm 0.2 \mathrm{hPa}$, (center) $0.2 \mathrm{hPa}$ from $\pm 0.1 \mathrm{hPa}$ and (right) $0.04 \mathrm{hPa}$ from $\pm 0.02 \mathrm{hPa}$, with dashed (dotted) contours for positive (negative) values. Dark (light) shading indicates positive (negative) MSLP and MSLP $2-10 \mathrm{~d}$ values that are significant at $5 \%$; $850 \mathrm{hPa}$ winds are shown only where significant at $5 \%$.

\subsection{EOTs driven by TCs}

DJF EOT 2 (Figure 3(b)) is the only EOT to display a significant relationship with the number of TCs approaching the Queensland coast. This EOT describes rainfall variability in tropical northern Queensland, where most of the TCs that strike Queensland make landfall (Flay and Nott, 2007). Even a single landfalling cyclone can substantially increase seasonal rainfall totals there (Lough, 1993). DJF EOT 2 shows no relationship with any other large-scale driver (Table I), despite the known influence of ENSO on tropical-cyclone counts near Queensland (Walsh and Syktus, 2003; Kuleshov et al., 2009). This may be due to the removal of the DJF EOT 1 pattern, which was highly correlated with ENSO and the IPO, prior to the calculation of EOT 2. Further, DJF EOT 1 is not associated with tropical-cyclone activity, despite the EOT being driven by ENSO. This is likely due to the state-wide nature of DJF EOT 1; variations in tropical-cyclone activity are far more likely to affect regional, coastal rainfall than state-wide patterns.

Composites of IBTrACS cyclone tracks were constructed for the six seasons in 1979-2010 - the period of the IBTrACS dataset (Section 2.3) - when DJF EOT 2 was above (Figure 8(a)) and below (Figure 8(b)) one standard deviation of its mean. The six strong DJF EOT 2 seasons clearly have far more TCs near the northeastern Queensland coast than the six weak seasons, with the main genesis region between $150^{\circ} \mathrm{E}$ and $170^{\circ} \mathrm{E}$. In weak years, many storms form east of $160^{\circ} \mathrm{E}$ and track south, away from Australia. Regressions on DJF EOT 2 of tropical-cyclone track, genesis and lysis densities from IBTrACS, computed using the method of Hodges (1996), were also analysed. The results were broadly similar to those for the composites in Figure 8: for above-normal DJF EOT 2 seasons, there were increases in track density near the Queensland coast, in genesis density in the Coral Sea and in lysis density over the Cape York peninsula. For brevity, these are not shown. Further, regressions onto DJF-mean 850-250 hPa vertical wind shear from 20CR showed reductions in wind shear across northern Australia in high DJF EOT 2 seasons (not shown). This is consistent with the conclusions of Camargo et al. (2007) and Kuleshov et al. (2009) on the importance of low vertical wind shear for tropical-cyclone development in the southwest Pacific.

\subsection{EOTs driven by monsoon variability}

Autumn is the only season for which the leading, statewide EOT shows no significant correlation with Pacific 

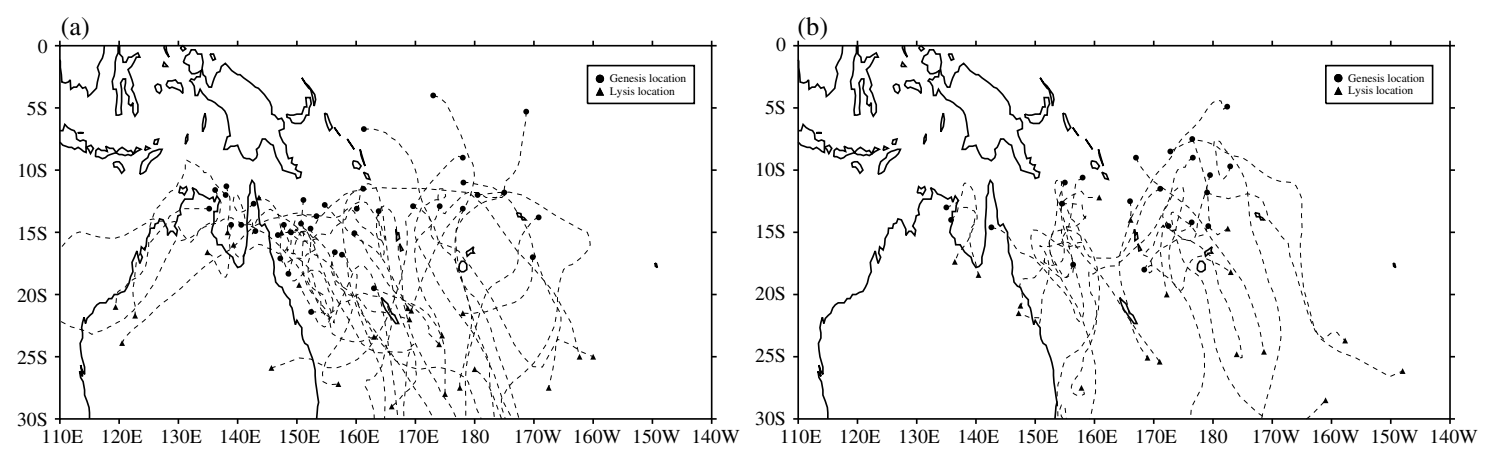

Figure 8. December-February tropical-cyclone tracks from IBTrACS for the six seasons in 1978-2007 when DJF EOT 2 is (a) greater than and (b) less than one standard deviation. A circle (triangle) indicates the genesis (lysis) location.

(a) MSLP and $850 \mathrm{hPa}$ winds

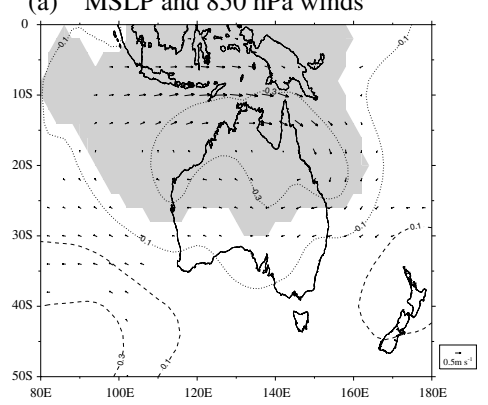

(b) SST

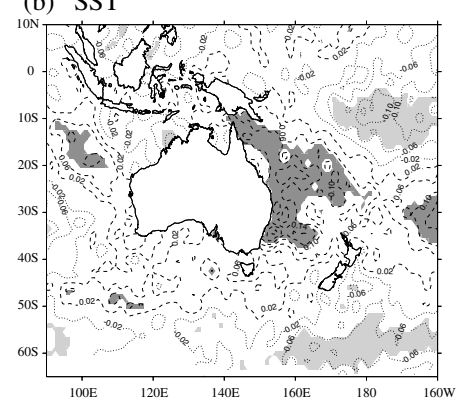

(c) 2-10 day filtered MSLP

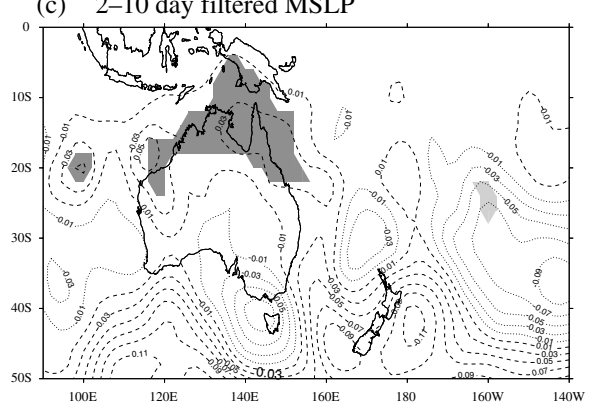

Figure 9. Regression coefficients for (a) MSLP (contours and shading) and $850 \mathrm{hPa}$ winds (vectors), (b) SSTs and (c) the seasonal standard deviation of $\mathrm{MSLP}_{2-10 \mathrm{~d}}$ on the MAM EOT 1 timeseries. The contour intervals are $0.2 \mathrm{hPa}$ from $\pm 0.1 \mathrm{hPa}$ for $\mathrm{MSLP}, 0.04{ }^{\circ} \mathrm{C}$ from $\pm 0.02{ }^{\circ} \mathrm{C}$ for SST and $0.02 \mathrm{hPa}$ from $\pm 0.01 \mathrm{hPa}$ for $\mathrm{MSLP}_{2-10 \mathrm{~d}}$, with positive (negative) contours dashed (dotted). Dark (light) shading indicates positive (negative) MSLP, SST and MSLP $_{2-10 d}$ regressions that are statistically significant at $5 \% ; 850$ hPa winds are shown only where significant at $5 \%$.

SST variability (Table I). Rather, the positive phase of MAM EOT 1 is associated with lower MSLP and an enhanced $850 \mathrm{hPa}$ cyclonic circulation at over much of Australia (Figure 9(a)), which suggests increased rainfall at the end of the monsoon season. Regressions of MAM EOT 1 onto monthly SILO rainfall support this link to monsoon: most of the rainfall variations associated with this EOT occur in March, with virtually no signal in April or May (not shown). The MAM EOT 1 timeseries is also significantly positively correlated $(r=+0.44$, significant at the $1 \%$ level) with the autumn-mean Australian monsoon index of Kajikawa et al. (2010). The index - defined as the mean $850 \mathrm{hPa}$ zonal wind across a box $5^{\circ}-15^{\circ} \mathrm{S}, 110^{\circ}-130^{\circ} \mathrm{E}$ - was computed from daily values from the 20CR; MAM seasonal means were taken prior to correlating the timeseries with MAM EOT 1.

Unlike the ENSO-driven MAM EOT 3, which was restricted to northern Queensland, in MAM EOT 1 the strong monsoon circulation extends over the entire state, bringing enhanced cyclonic, onshore winds to central and southern Queensland. The MAM EOT $1850 \mathrm{hPa}$ circulation resembles DJF EOT 1 (Figure 5(f)), with the key difference that in MAM there is no anomalous convergence over the Maritime Continent. There is no link between MAM EOT 1 and the Walker Circulation, consistent with the lack of an association with ENSO and the IPO. This is likely because the influence of ENSO wanes in austral autumn, during which it affects only the tropical north of the state, as represented by MAM EOT 3 (Section 4.1). While DJF EOT 1 and MAM EOT 1 are each related to the strength of the Australian monsoon, their timeseries are uncorrelated $(r=+0.02)$. Again, this is likely because of the influence of ENSO on the summer state-wide pattern, but not on the autumn one. Section 5 further discusses the correlations between EOTs

Instead, local SST anomalies dominate: warm SSTs along the eastern coast accompany wet autumns in Queensland (Figure 9(b)). Local air-sea interactions may therefore play an important role in determining statewide rainfall during the final phase of the monsoon. Previous studies have demonstrated key roles for feedbacks between monsoon circulations and local SST anomalies in the Australian and South Asian monsoon systems (Nicholls, 1978; Meehl, 1997; Wang et al., 2003). Here, the warm SSTs coincide with increased synoptic activity across Queensland and northern Australia, as measured by the seasonal standard deviation in MSLP $_{2-10 d}$ (Figure 9(c)). When combined with the lower seasonal-mean MSLP and increased cyclonic circulation (Figure 9(a)), this stronger variability suggests more-frequent cyclonic activity and more rain-bearing monsoon disturbances.

\subsection{EOTs driven by local synoptic patterns}

Three EOTs that affect southern and southeastern Queensland - DJF EOT 3, MAM EOT 2 and JJA EOT 2 - do 


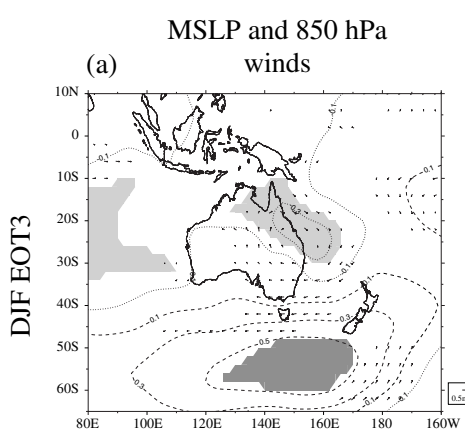

(d)
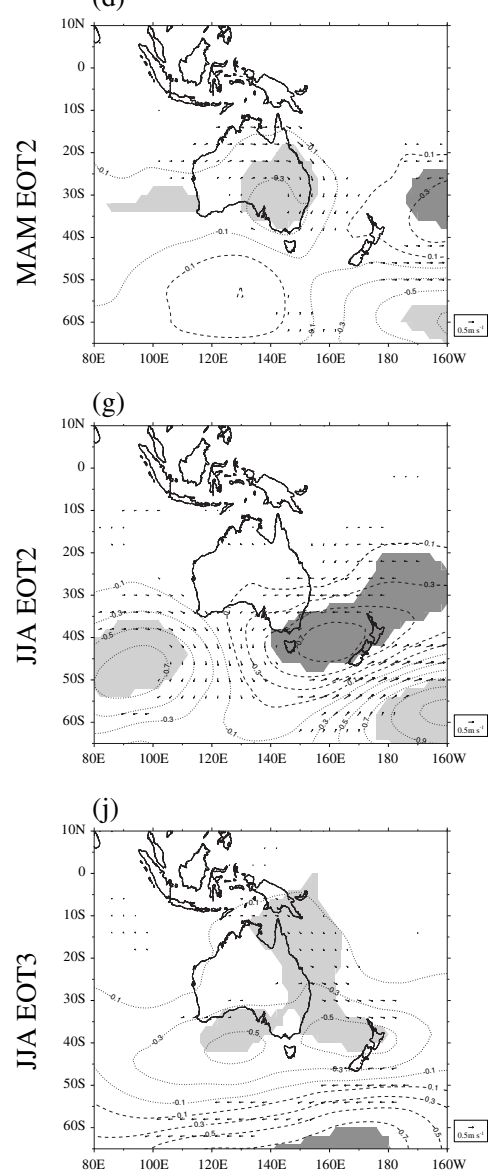

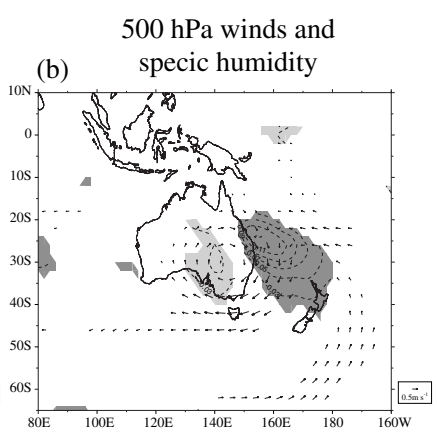

(e)
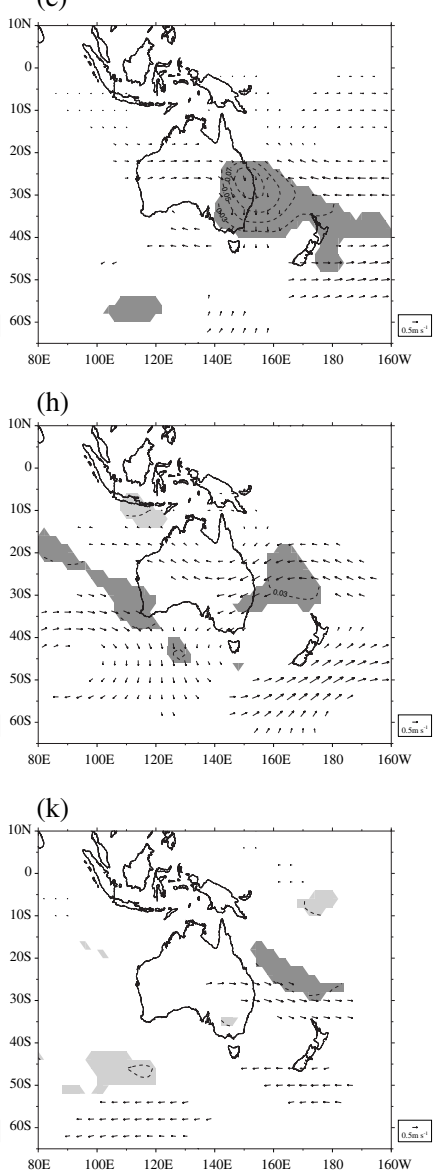

(c) 2-10 day filtered MSLP

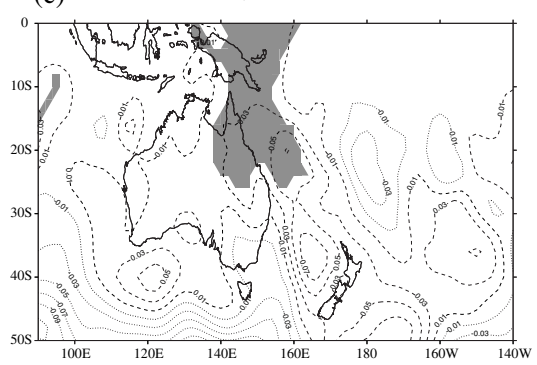

(f)
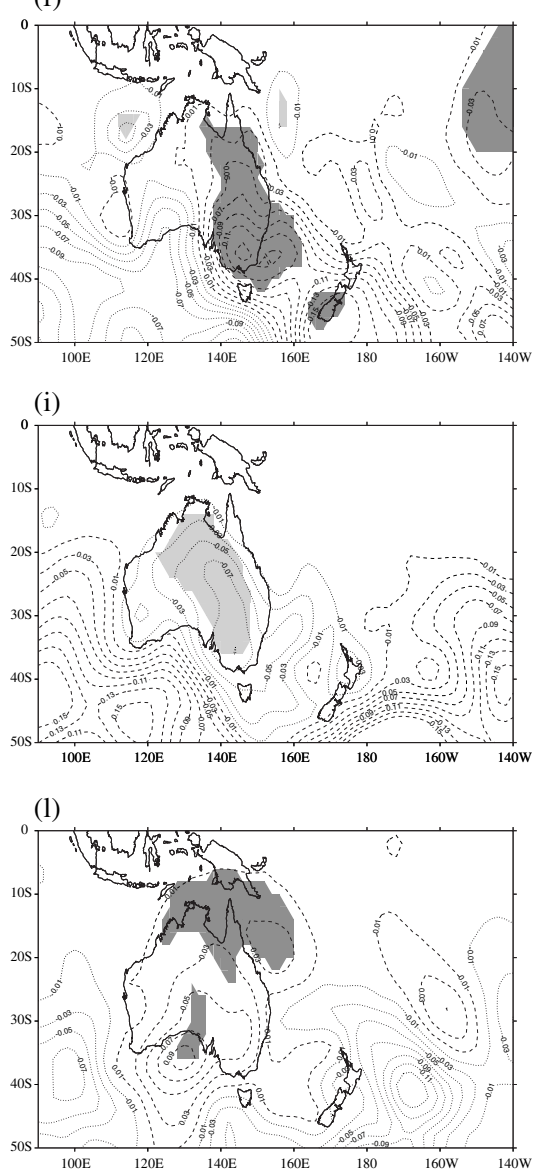

Figure 10. For (top row) DJF EOT 3, (second row) MAM EOT 2, (third row) JJA EOT 2 and (fourth row) JJA EOT 3, the linear regression coefficients of (left column) seasonal-mean MSLP (contours and shading) and $850 \mathrm{hPa}$ winds (vectors); (center column) seasonal-mean $500 \mathrm{hPa}$ specific humidity (contours and shading) and $500 \mathrm{hPa}$ winds (vectors); and (right column) the seasonal standard deviation of $\mathrm{MSLP}_{2-10 \mathrm{~d}}$ onto each EOT timeseries. The contour intervals are $0.2 \mathrm{hPa}$ from $\pm 0.1 \mathrm{hPa}$ for MSLP, $0.02 \mathrm{~g} \mathrm{~kg}^{-1}$ from $\pm 0.01 \mathrm{~g} \mathrm{~kg}^{-1}$ for specific humidity and $0.02 \mathrm{hPa}$ from $\pm 0.01 \mathrm{hPa}$ for $\mathrm{MSLP}_{2-10 \mathrm{~d}}$, with positive (negative) contours dashed (dotted). Dark (light) shading indicates where positive (negative) MSLP, specific humidity and MSLP $_{2-10 \mathrm{~d}}$ regressions are significant at 5\%; 850 and $500 \mathrm{hPa}$ winds are shown only where significant at $5 \%$.

not show statistically significant correlations with many of the large-scale drivers considered (Table I), but instead are linked to local circulations and synoptic activity. Each EOT displays significant decadal or multi-decadal variability for much of 1900-2010 (Figure 4), which demonstrates that local Australian synoptic patterns have natural, internal variability on these temporal scales, separate from external forcing (e.g. from Pacific SSTs). A fourth EOT - JJA EOT 3 - is correlated with the SAM, but this section demonstrates it is likely driven by local synoptic patterns.
DJF EOT 3 describes rainfall variations in coastal southern Queensland (Figure 3(c)). Seasons of high coastal summer rainfall are associated with anomalously low MSLP over coastal Queensland and anomalously high pressure in the Southern Ocean, southwest of New Zealand (Figure 10(a)). The $850 \mathrm{hPa}$ circulation around the anomalous MSLP dipole brings anomalous onshore winds to southern Queensland, enhancing oceanto-land moisture transport. Mid-tropospheric (500 hPa) specific humidity increases along the coast, associated with a cyclonic circulation over southeastern Australia 
that draws tropical air southeast (Figure 10(b)). Increases in MSLP $_{2-10 d}$ variance are collocated with the reduced MSLP, implying more-frequent coastal cyclonic activity (Figure 10(c)). DJF EOT 3 is unrelated to TCs (not shown), but may be connected to the number of coastal monsoon lows. As the anomalous Southern Ocean anticyclone and the anomalous $500 \mathrm{hPa}$ easterlies near $45^{\circ} \mathrm{S}$ suggest, this EOT is correlated with $\mathrm{B}_{120-150}$ (Table I). Since Queensland receives most of its summer rainfall from tropical, not extra-tropical systems, blocking likely plays only a small role in directing rain-bearing systems towards Queensland. The negative loading of this pattern since 1970 (Figure 4(c)) implies a decrease in the frequency of coastal depressions and onshore flow over the last four decades.

In autumn, EOT 2 is centred over central and southern Queensland (Figure 3(e)). The spatial pattern is nearly the complement of the ENSO-driven MAM EOT 3 (Figure 3(f)). Thus, once the state-wide EOT 1 has been removed, EOT 2 describes coherent rainfall variations in regions that are unaffected by ENSO. Unlike DJF EOT 3, MAM EOT 2 is clearly associated with extra-tropical synoptic patterns, with an anomalous surface cyclonic circulation over southeastern Australia (Figure 10(d)) and mid-tropospheric convergence and moistening along the east coast (Figure 10(e)). The MSLP anomalies are linked to enhanced MSLP $_{2-10 d}$ variance across eastern Australia (Figure 10(f)). While the tracks of individual systems cannot be determined from these diagnostics, the negative MSLP anomalies and the maximum in MSLP variance over southeastern Australia suggest that these are extratropical systems that move north and east from there, bringing rain to central and southern Queensland.

JJA EOT 2 describes opposing rainfall variations in southeastern and western Queensland (Figure 3(h)). Since 1990, the EOT has been in a negative phase of its multi-decadal oscillation (Figure 4(h)), corresponding to dry (wet) conditions in the southeast (west). In years of high JJA EOT 2, an anomalous Tasman Sea anti-cyclone drives onshore $850 \mathrm{hPa}$ (Figure $10(\mathrm{~g})$ ) and $500 \mathrm{hPa}$ (Figure 10(h)) winds along the coast, leading to enhanced moisture transport and increased rainfall. The EOT is significantly correlated with $\mathrm{B}_{150-180}$ (Table I), consistent with the reductions in synoptic activity across southeastern and central-eastern Australia (Figure 10(i)). Blocking often causes Southern Ocean cyclones to deviate southeast, away from Australia. The reduced synoptic activity likely explains the reduced rainfall in western Queensland in years of positive JJA EOT 2. Thus, wintertime Tasman Sea blocking increases (reduces) rainfall in southeastern (western) Queensland via strengthened onshore winds (fewer extra-tropical cyclones).

We note that Risbey et al., 2009b) found positive correlations between JJA blocking at $140^{\circ} \mathrm{E}$ and western Queensland rainfall (their Fig. 13c), which the authors attributed to cut-off lows forming north of the block. The blocking associated with JJA EOT 2 is located east of the longitude Risbey et al. (2009b) used, which may explain the variation in rainfall impacts: cut-off lows forming north of the Tasman Sea block may be too far east to affect western Queensland. Further, Risbey et al. (2009b) computed the correlation with the total seasonal rainfall, whereas JJA EOT 2 represents only that portion of the rainfall that varies coherently between western and southeastern Queensland.

While JJA EOT 3, representing central and northern Queensland (Figure 3(i)), is negatively correlated with the SAM (Table I), regressions of 20CR MSLP onto JJA EOT 3 for the period of the SAM index (1958-2007) do not resemble the observed annular SAM structure (Figure 11). Rather, the only statistically significant correlations occur between Australia and Antarctica. These negative anomalies would project onto the negative SAM, explaining the correlation, but it is doubtful that the SAM drives this EOT. Hendon et al. (2007) and Risbey et al. (2009b) concluded that the SAM affects only southern Victoria and southern Western Australia in JJA.

Instead, JJA EOT 3 is likely associated with coastal cyclones. Low pressures southeast of Australia and along the east coast (Figure 10(j)), combined with increased synoptic activity across Queensland and offshore (Figure 10(1)), support this association. The coastal $850 \mathrm{hPa}$ circulation patterns resemble those for MAM EOT 2, which is also linked the southward transport of tropical air and coastal synoptic activity. The $500 \mathrm{hPa}$ circulation anomalies are weaker than for MAM EOT 2, with no convergence or moistening (Figure 10(k)). Still, the increases in synoptic activity point to the importance of coastal storms that can draw tropical moisture south. JJA EOT 3 does not explain rainfall in the southern coastal regions, despite increases in synoptic activity; this is due to the removal of JJA EOT 2, which explained most of the variance in southeastern rainfall. JJA EOTs 2

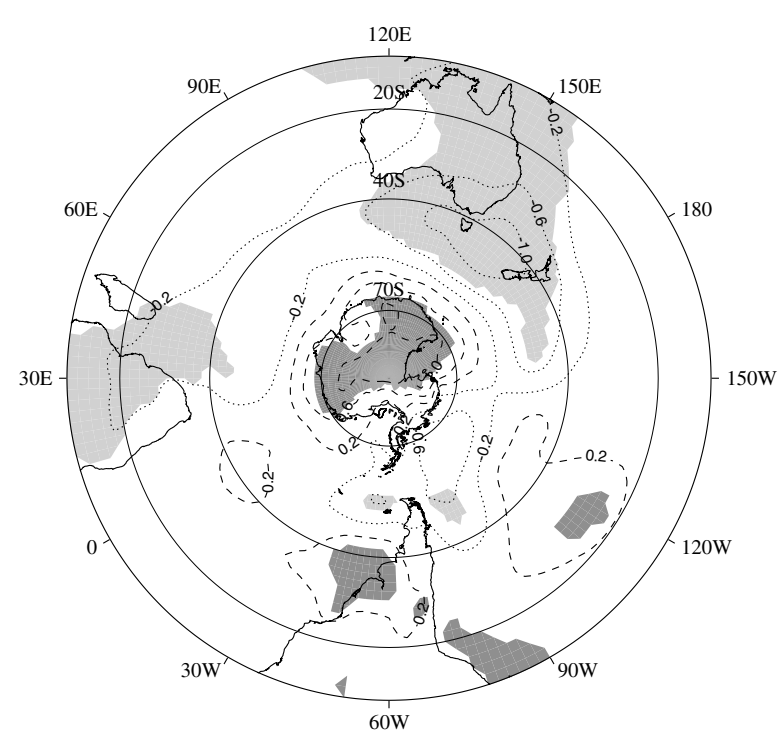

Figure 11. Linear regression coefficients of 20CR MSLP regressed onto JJA EOT 3 for 1958-2007, the period of the observed SAM index. The contour interval is $0.4 \mathrm{hPa}$ from $\pm 0.2 \mathrm{hPa}$, with dashed (dotted) contours for positive (negative) values. Dark (light) shading indicates positive (negative) values that are statistically significant at $5 \%$. 

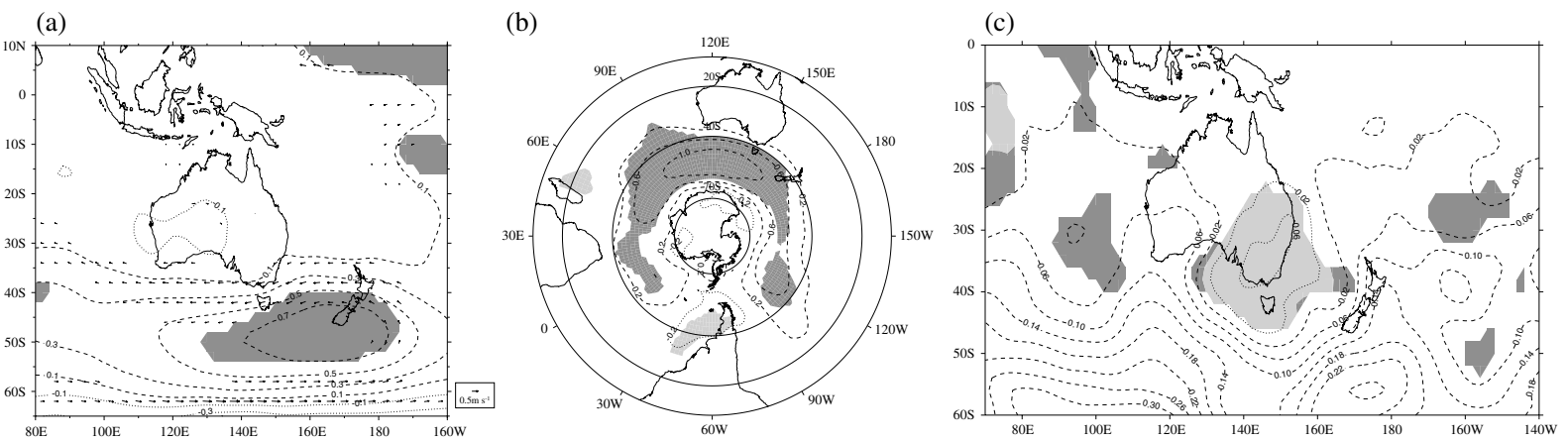

Figure 12. Linear regression coefficients of (a) seasonal-mean 20CR MSLP (contours and shading) and $850 \mathrm{hPa}$ winds (vectors); (b) seasonal-mean 20CR MSLP in a polar stereographic projection; (c) the seasonal standard deviation of 20CR MSLP $2-10 \mathrm{~d}$ onto the timeseries of SON EOT 3. The contour interval is $0.2 \mathrm{hPa}$ from $\pm 0.1 \mathrm{hPa}$ for MSLP and $0.02 \mathrm{hPa}$ from $\pm 0.01 \mathrm{hPa}$ for MSLP $2_{2-10 \mathrm{~d}}$, with positive (negative) contours dashed (dotted). Dark (light) shading indicates statistically significant positive (negative) MSLP values at the 5\% level; $850 \mathrm{hPa}$ winds are shown only where statistically significant at the $5 \%$ level.

Table II. A summary of the EOT analysis, giving for each EOT the percentage of variance explained in Queensland-average rainfall, the region of Queensland encompassed by the pattern, and the likely driving mechanism.

\begin{tabular}{lrll}
\hline EOT & Var. expl. & Region affected & Likely driving mechanism \\
\hline DJF & & & \\
EOT 1 & $37.71 \%$ & State-wide & ENSO (peaking) effects on Australian monsoon, modulated by the IPO \\
EOT 2 & $8.63 \%$ & Cape York & $\begin{array}{l}\text { Tropical cyclone activity in the Coral Sea } \\
\text { Coastal cyclones and onshore winds }\end{array}$ \\
EOT 3 & $7.36 \%$ & Southern & \\
MAM & & & Strength of late-season monsoon, local air-sea interactions \\
EOT 1 & $32.17 \%$ & State-wide & Extra-tropical storm track, 500 hPa convergence and moistening along the coast \\
EOT 2 & $13.54 \%$ & Central and southern & ENSO (decaying) effects on late-season Australian monsoon, restricted to tropics \\
EOT 3 & $8.64 \%$ & Northern & \\
JJA & & & ENSO (developing) and SAM influences on extra-tropical storm track \\
EOT 1 & $45.12 \%$ & State-wide & Blocking in Tasman Sea, driving onshore winds and onshore moisture transport \\
EOT 2 & $9.85 \%$ & Southeastern and western & Coastal cyclones, southward transport of tropical moisture \\
EOT 3 & $6.63 \%$ & Northern & \\
SON & & & ENSO (developing) and SAM influences on extra-tropical storm track \\
EOT 1 & $41.34 \%$ & State-wide & ENSO (decaying), southward transport of tropical moisture \\
EOT 2 & $10.91 \%$ & Northern & Unclear, but associations with SAM and Southern Ocean blocking \\
EOT 3 & $6.80 \%$ & Southeastern & \\
\hline
\end{tabular}

and 3 demonstrate the importance of extra-tropical synoptic circulations for winter rainfall in southern and central Queensland, respectively.

\subsection{The third spring EOT}

SON EOT 3 is centred in the southeast (Figure 3(1)); it is correlated with the SAM and with $\mathrm{B}_{120-150}$ (Table I). Features of these drivers can be seen in MSLP and $850 \mathrm{hPa}$ circulation regressions (Figure 12(a) and (b)), but there are no significant anomalies over Queensland. Seasonal synoptic variability decreases over eastern and southeastern Australia (Figure 12(c)), consistent with the strong Southern Ocean blocking. Hendon et al. (2007) and Meneghini et al. (2007) found that the positive SAM could increase spring rainfall in coastal eastern Australia via anomalous onshore winds, but no such circulation patterns are found for SON EOT 3 in either 20CR (Figure 12(a)) or ERA-40 (not shown). While this EOT is related to blocking and the SAM, no conclusions can be drawn about how those influence southeastern Queensland spring rainfall.

\section{Discussion and summary}

EOT analysis has been used to decompose the interannual variability in seasonal Queensland rainfall for 1900-2010 into patterns that are linearly orthogonal in time. Regressions of the three leading EOTs for each season against observations and reanalysis data have allowed diagnosis of the drivers of Queensland's rainfall variability and the seasonal variations in their strength (Table II). Beyond the first, state-wide EOT for each season, the EOT decomposition identified regions of Queensland that vary coherently. In many cases, this permitted some separation of the effects of individual drivers on the state. For example, variations in the number of Coral Sea TCs control summer rainfall in the Cape York peninsula (DJF EOT 2, Section 4.2); in southern 
Queensland, summer rainfall is driven by fluctuations in east-coast cyclone numbers and the strength of onshore winds (DJF EOT 3, Section 4.4).

In spring, summer and winter, the leading, state-wide pattern of Queensland rainfall variability is highly correlated with the ENSO (Table I). This reinforces the conclusions of Risbey et al. (2009b) and many others, who have found that the ENSO explains the greatest rainfall variance in Queensland of any single driver. During the autumn ENSO transition season, Pacific SST variability is associated with rainfall in only tropical northern Queensland (MAM EOT 3; Figure 5(b)). In spring and winter, the correlation between EOT 1 and Niño 4 SSTs has been mostly stable since 1900 , with only weak decadal fluctuations. By contrast, the relationship between summer rainfall and Niño 4 has varied considerably, coherent with shifts in the IPO (Section 4.1): in IPO warm (cool) phases, the correlation between DJF EOT 1 and Niño 4 is weak (strong). Additionally, DJF EOT 1 shows a greater correlation with a seasonal IPO index than with Niño 4 (Table I); it is the only EOT associated with off-equatorial as well as equatorial Pacific SST anomalies (Figure 5(a)); and it is the only ENSO-related EOT to display consistent, significant multi-decadal variability (Figure 4(a)). These results suggest a much more substantial impact of the IPO on Queensland rainfall in summer than in winter or spring.

In winter and spring, Queensland rainfall is influenced by the tropical and extra-tropical circulation responses to the ENSO (Figure 5(h) and (i)), as well as shifts in the Southern Ocean storm track and fluctuations in blocking activity that are likely related to SAM variability (Figure 7). It has not been possible to separate the impacts of the ENSO and the SAM on JJA EOT 1 and SON EOT 1, but the analysis in Section 4.1 points to a potentially greater role for extra-tropical ENSO teleconnections and the SAM to affect state-wide Queensland rainfall than has previously been reported. The spring season is unique in that variations in ENSO character affect the teleconnection to Queensland rainfall: strengthening ENSO events that peak in the next DJF cause state-wide rainfall anomalies (SON EOT 1), while ENSO events that stagnate or decay in the next DJF impact northern Queensland only (SON EOT 2; Figure 6(b)).

State-wide autumn rainfall variations are controlled by the late-season strength of the Australian monsoon (Figure 9(a)). The warm SST anomalies along the east coast of Australia (Figure 9(b)) and the increased synoptic variability across Queensland (Figure 9(c)) suggest that local air-sea interactions are important for maintaining the monsoon rains into autumn, absent of the influence of the ENSO.

Once the state-wide, EOT 1 patterns have been removed, the EOTs describing summer (DJF EOT 3), autumn (MAM EOT 2) and winter (JJA EOT 2) rainfall in southern Queensland are associated with variability in local, coastal synoptic patterns, particularly onshore winds and Tasman Sea blocking (Section 4.4). All three EOTs have been negative since at least 1990 (Figure 4(f), (g) and (i)), with DJF EOT 3 negative since 1970. This variability is almost certainly linked to recent declines in coastal and southern Queensland rainfall (Alexander et al., 2007; Gallant et al., 2007). These EOTs also demonstrate significant decadal or multi-decadal variability (Figure 4), but are not linked to the IPO or any other remote driver considered in this study (Table I). Thus, it is probable that the coastal circulation regimes themselves exhibit natural, internal variability on these temporal scales, and thus modulate rainfall. Future work should focus on understanding precisely what types of rainbearing systems (e.g. east-coast lows; Hopkins and Holland, 1997) are associated with these EOTs, and whether the frequencies of those systems also show decadal variability. Improved knowledge of the sources of natural decadal variability in Australian rainfall would greatly aid predictions of rainfall changes over the next several decades.

As is often the case with decomposition techniques, it has not been possible to associate all of the EOTs with a driver; the mechanism that controls spring rainfall in southeastern Queensland (SON EOT 3) remains unclear. The pattern is associated with Southern Ocean blocking and the positive SAM, but the lack of any significant circulation, MSLP, or SST anomalies near the region of interest make it impossible to ascertain how these drivers control rainfall.

To assess whether the identified EOTs would be useful for seasonal prediction, we performed lead-lag correlation analysis between each EOT and all other EOTs, using 1- and 2-year leads and lags (not shown). The only EOTs that showed statistically significant correlations were the ENSO-driven EOTs, which were significantly correlated only with other ENSO-driven EOTs. This likely reflects nothing more than the persistence of ENSO from one season to the next within a calendar year. These results may point to an inherent lack of predictability in Queensland rainfall, at least based on past seasons' rainfall alone, apart from the teleconnection with ENSO. We note that Hendon et al. (2012) demonstrated low potential predictability for the Australian summer monsoon, during which Queensland receives much of its rainfall, due to seasonally reversing air-sea interactions in the waters north of Australia.

Based on this study and the results of Smith (2004) and Rotstayn et al., 2010), the EOT technique has proven useful in separating Australian rainfall into regional patterns of variability, and in identifying atmospheric and coupled atmosphere-ocean drivers of that variability. Applying this same EOT analysis to the control simulations of coupled climate models would permit a rigorous assessment of the models' abilities to simulate not only Queensland's rainfall, but also the mechanisms that control its variability. Those mechanisms that were well-simulated could then be investigated in model integrations with increased greenhouse-gas concentrations, with the ultimate goal of reducing uncertainty in projections of future rainfall change. 
None of the EOTs displayed a statistically significant linear trend over the 1900-2010 study period, while only a few EOTs had any significant running 30-year linear trends. This suggests that (1) the timeseries of rainfall in Queensland is dominated by variability, rather than a slowly evolving trend, and (2) the impacts of the drivers considered here are mostly stable on temporal scales longer than 20-30 years. To understand and predict changes in Queensland rainfall, therefore, requires further investigations of the processes by which the rainfall drivers vary inter-annually and decadally, and how those variations are expressed in the spatial and temporal variability of rainfall.

\section{Acknowledgements}

NPK was funded by a grant from the Queensland Government, under a collaboration between the Queensland Climate Change Centre of Excellence and the Walker Institute. SJW was funded by a grant from the National Centre for Atmospheric Science, a collaborative centre of the Natural Environment Research Council. NPK and JS acknowledge productive discussions on EOT analysis with Ian Smith of the Commonwealth Scientific and Industrial Research Organisation. Ian Smith also provided useful comments on a previous version of the manuscript, which helped to refine its focus and improve its organization. SILO rainfall data were provided by the Queensland Government. 20th Century Reanalysis V2 data were provided by the NOAA/OAR/ESRL PSD, Boulder, Colorado, USA, from their Web site at http://www.esrl.noaa.gov/psd/. Support for the Twentieth Century Reanalysis Project dataset is provided by the U.S. Department of Energy, Office of Science Innovative and Novel Computational Impact on Theory and Experiment (DOE INCITE) program, and Office of Biological and Environmental Research (BER), and by the National Oceanic and Atmospheric Administration Climate Program Office. HadISST SSTs were provided by the British Atmospheric Data Centre, under agreement with the U.K. Met Office. IBTrACS data were provided by the U.S. National Climatic Data Center.

\section{References}

Alexander LV, Hope P, Collins D, Trewin B, Lynch A, Nicholls N 2007. Trends in Australia's climate means and extremes: a global context. Australian Meteorological Magazine 56: 1-18.

Allan R. 1988. El Niño Southern Oscillation influences in the Australasian region. Progress in Physical Geography 12: 313-348.

Arblaster J, Meehl G, Moore A. 2002. Interdecadal modulation of Australian rainfall. Climate Dynamics 18: 519-531.

Cai W, van Rench P, Cowan T, Sullivan A. 2010. Asymmetry in ENSO teleconnection with regional rainfall, its multidecadal variability, and impact. Journal of Climate 23: 4944-4955.

Cai W, Whetton PH, Pittock AB. 2001. Fluctuations of the relationship between ENSO and northeast Australian rainfall. Climate Dynamics 17: $421-432$.

Callaghan J, Power SB. 2011. Variability and decline in the number of severe tropical cyclones making land-fall over eastern Australia since the late nineteenth century. Climate Dynamics 37: 647-662, DOI: $10.1007 /$ s00382-010-0883-2.
Camargo SJ, Emanuel KA, Sobel AH. 2007. Use of a genesis potential index to diagnose ENSO effects of tropical cyclone genesis. Journal of Climate 20: 4819-4834.

Compo G, Whittaker JS, Sardeshmukh PD, Matsui N, Allan RJ, Yin X, Gleason BE, Vose RS, Rutledge G, Bessemoulin P, Bronnimann S, Brunet M, Crouthamel RI, Grant AN, Groisman PY, Jones PD, Kruk MC, Kruger AC, Marshall GJ, Maugeri M, Mok HY, Nordli O, Ross TF, Trigo RM, Wang XL, Woodruff SD, Worley SJ. 2011. The twentieth century reanalysis project. Quarterly Journal of the Royal Meteorological Society 137: 1-28.

Flay S, Nott J. 2007. Effect of ENSO on Queensland seasonal landfalling cyclone activity. International Journal of Climatology 27: $1327-1334$.

Folland CK, Renwick JA, Salinger MJ, Mullan AB. 2002. Relative influences of the Interdecadal Pacific Oscillation and ENSO on the South Pacific convergence zone. Geophysical Research Letters 29: 1643.

Gallant AJE, Hennessy KJ, Risbey J. 2007. Trends in rainfall indices for six Australian regions: 1910-2005. Australian Meteorological Magazine 56: 223-239.

Gong D, Wang S. 1999. Definition of Antarctic Oscillation index. Geophysical Research Letters 26: 459-462.

Grant AP, Walsh KJE. 2001. Interdecadal variability in north-east Australia tropical cyclone formation. Atmospheric Science Letters 2: $9-17$.

Hastings P. 1990. Southern Oscillation influences on tropical cyclone activity in the Australia/Southwest Pacific region. International Journal of Climatology 10: 291-298.

Hendon D, Thompson D, Wheeler M. 2007. Australian rainfall and surface temperature variations associated with the Southern Annular Mode. Journal of Climate 20: 2452-2467.

Hendon HH, Lim E-A, Lin G. 2012. The role of air-sea interaction for prediction of Australian summer monsoon rainfall. Journal of Climate 25: 1278-1290.

Hennessy KJ, Suppiah R, Page CM. 1999. Australian rainfall changes, 1910-1995. Australian Meteorological Magazine 48: 1-13.

Hodges KI. 1996. Spherical nonparametric estimators applied to the UGAMP model integration for AMIP. Monthly Weather Review 124: 2914-2932.

Holland GJ. 1997. The maximum potential intensity of tropical cyclones. Journal of Atmospheric Sciences 54: 2519-2541.

Hopkins LC, Holland GJ. 1997. Australian heavy-rainfall days and associated east-coast cyclones: 1958-92. Journal of Climate 10: $621-635$.

Jeffrey SJ. 2001. Using spatial interpolation to construct a comprehensive archive of Australian climate data. Environmental Modelling and Software 16: 309-330.

Kajikawa Y, Wang B, Yang J. 2010. A multi-time scale Australian monsoon index. International Journal of Climatology 30: 1114-1120, DOI: 10.1002/joc. 1955.

Karoly DJ. 1989. Southern Hemisphere circulation features associated with El Niño-Southern Oscillation events. Journal of Climate 2: 1239-1252.

Knapp KR, Kruk MC, Levinson DH, Diamond HJ, Neumann CJ. 2010. The international best track archive for climate stewardship (IBTrACS). Bulletin of the American Meteorological Society 91: 363-376.

Kuleshov Y, Ming FC, Qi L, Chouaibou I, Hoareau C, Roux F. 2009. Tropical cyclone genesis in the Southern Hemisphere and its relationship with ENSO. Annals of Geophysics 27: 2523-2538.

Lavery BM, Joung G, Nicholls N. 1997. An extended high-quality historical rainfall dataset for Australia. Australian Meteorological Magazine 46: 27-38.

Lejenäs H. 1984. Characteristics of southern hemisphere blocking as determined from a time series of observed data. Quarterly Journal of the Royal Meteorological Society 110: 967-979.

Lough JM. 1991. Rainfall variations in Queensland, Australia. International Journal of Climatology 11: 745-768.

Lough JM. 1993. Variations of some season rainfall characteristics in Queensland, Australia: 1921-1987. International Journal of Climatology 13: 391-409.

Lough JM. 1997. Regional indices of climate variation: temperature and rainfall in Queensland, Australia. International Journal of Climatology 17: 55-66.

Marshall G. 2003. Trends in the southern annual mode from observations and reanalyses. Journal of Climate 16: 4134-4143. 
McBride JL, Nicholls N. 1983. Seasonal relationships between Australian rainfall and the Southern Oscillation. Monthly Weather Review 111: 1998-2004.

Meehl G. 1997. The South Asian monsoon and the Tropospheric Biennial Oscillation. Journal of Climate 10: 1921-1943.

Meneghini B, Simmonds I, Smith I. 2007. Association between Australian rainfall and the Southern Annular Mode. International Journal of Climatology 27: 109-121.

Mo KC. 2000. Relationships between low-frequency variability in the Southern Hemisphere and sea surface temperature anomalies. Journal of Climate 13: 3599-3610.

Murphy BF, Ribbe J. 2004. Variability of southeastern Queensland rainfall and climate indices. International Journal of Climatology 24: $703-721$.

Newman M, Compo GP, Alexander MA. 2003. ENSO-forced variability of the Pacific Decadal Oscillation. Journal of Climate 16: 3853-3857.

Nicholls N. 1978. Air-sea interaction and the quasi-biennial oscillation. Monthly Weather Review 106: 1505-1508.

Nicholls N. 1989. Sea surface temperatures and Australian winter rainfall. Journal of Climate 2: 965-973.

Nicholls N, Lavery B. 1992. Australian rainfall trends during the twentieth century. International Journal of Climatology 12: $153-163$.

Parker D, Folland C, Scaife A, Knight J, Colman A, Baines P, Dong B. 2007. Decadal to multidecadal variability and the climate change background. Journal of Geophysical Research 112: D18115.

Pook M, Gibson T. 1999. Atmospheric blocking and storm tracks during SOP-1 of the FROST project. Australian Meteorological Magazine Spec. Ed.: 51-60.

Pook M, McIntosh P, Meyers G. 2006. The synoptic decomposition of cool-season rainfall in the Southern Australian cropping region. Journal of Applied Meteorology and Climatology 45: 1156-1170.

Power S, Casey T, Folland C, Colman A, Mehta V. 1999. Interdecadal modulation of the impact of ENSO on Australia. Climate Dynamics 15: 319-324.

Power S, Haylock M, Colman R, Wang X. 2006. The predictability of interdecadal changes in ENSO activity and ENSO teleconnections. Journal of Climate 19: 4755-4771.

Qi L, Leslie LM, Zhao SX. 1999. Cut-off low pressure systems over Southern Australia: climatology and case study. International Journal of Climatology 19: 1633-1649.

Rayner NA, Brohan P, Parker DE, Folland CK, Kennedy JJ, Vanicek M, Ansell T, Tett SFB. 2006. Improved analyses of changes and uncertainties in sea-surface temperatures measured in situ since the mid-nineteenth century: the HadSST2 data set. Journal of Climate 19: 446-4469.

Rayner NA, Parker DE, Horton EB, Folland CK, Alexander LV, Rowell DP, Kent EC, Kaplan A. 2003. Global analyses of sea surface temperature, sea ice and night marine air temperature since the late nineteenth century. Journal of Geophysical Research 108: 4407.

Renwick JA, Revell MJ. 1999. Blocking over the South Pacific and Rossby wave propagation. Monthly Weather Review 127: 2233-2247.

Risbey JS, Pook MJ, McIntosh PC, Ummenhofer CC, Meyers G. 2009a. Characteristics and variability of synoptic features associated with cool season rainfall in southeastern Australia. International Journal of Climatology 29: 1595-1613.
Risbey JS, Pook MJ, McIntosh PC, Wheeler MC, Hendon HH. 2009b. On the remote drivers of rainfall variability in Australia. Monthly Weather Review 137: 3233-3253.

Rogers JC, van Loon JC. 1982. Spatial variability of sea-level pressure and 500-mb height anomalies over the Southern Hemisphere. Monthly Weather Review 110: 1375-1392.

Rotstayn LD, Collier MA, Dix MR, Feng Y, Gordon HB, O'Farrell SP, Smith IN, Syktus J. 2010. Improved simulation of Australian climate and ENSO-related rainfall variability in a global climate model with an interactive aerosol treatment. International Journal of Climatology 30: $1067-1088$.

Saji NH, Goswami BN, Vinayachandran PN, Yamagata T. 1999. A dipole mode in the tropical Indian Ocean. Nature 401: 360-363.

Smith I. 2004. An assessment of recent trends in Australian rainfall Australian Meteorological Magazine 53: 163-173.

Smith IN, Timbal B. 2010. Links between tropical indices and southern Australian rainfall. International Journal of Climatology 32: 33-40.

Speer MS. 2008. On the late twentieth century decrease in Australian east coast rainfall extremes. Atmospheric Science Letters 9: 160-170.

Speer MS, Leslie MS, Fierro AO. 2011. Australian east coast rainfall decline related to large scale climate drivers. Climate Dynamics 36 : 1419-1429, DOI: 10.1007/s003 82-009-0726-1.

Thompson D, Solomon S. 2002. Interpretation of recent Southern Hemisphere climate change. Science 296: 895-899.

Thompson DWJ, Wallace JM. 2000. Annular modes in the extratropical circulation. Part I. Month-to-month variability. Journal of Climate 13: $1018-1036$.

Torrence C, Compo GP. 1998. A practical guide to wavelet analysis. Bulletin of the American Meteorological Society 13: 61-78.

Trenberth K, Mo K. 1985. Blocking in the Southern Hemisphere. Monthly Weather Review 113: 3-21.

Uppala SM, Kallberg PW, Simmons AJ, Andrae U, Da Costa Bechtold V, Fiorino M, Gibson JK, Haseler J, Hernandez A, Kelly GA, Li X, Onogi K, Saarinen S, Sokka N, Allan RP, Andersson E, Arpe K, Balmaseda MA, Beljaars ACM, Van De Berg L, Bidlot J, Bormann N, Caires S, Chevallier F, Dethof A, Dragosavac M, Fisher M, Fuentes M, Hagemann S, Holm E, Hoskins BJ, Isaksen L, Janssen PAEM, Jenne R, Mcnally AP, Mahfouf J-F, Morcrette J-J, Rayner NA, Saunders RW, Simon P, Sterl A, Trenberth KE, Untch A, Vasiljevic D, Viterbo P, Woollen J. 2005. The ERA-40 re-analysis. Quarterly Journal of the Royal Meteorological Society 131: 2961-3012.

Van Den Dool HM, Saha S, Johannson Å. 2000. Empirical orthogonal teleconnections. Journal of Climate 13: 1421-1435.

Walsh KJE, Nguyen KC, McGregor JL. 2004. Fine-resolution regional climate model simulations of the impact of climate change on tropical cyclones near Australia. Climate Dynamics 22: 47-56.

Walsh KJE, Syktus J. 2003. Simulations of observed interannual variability of tropical cyclone formation east of Australia. Atmospheric Science Letters 4: 28-40.

Wang B, Wu R, Li T. 2003. Atmosphere-warm ocean interaction and its impact on Asian-Australian monsoon variation. Journal of Climate 16: 1195-1211.

Wang G, Hendon H. 2007. Sensitivity of Australian rainfall to inter-El Niño variations. Journal of Climate 20: 4211-4226.

Webster PJ, Yang S. 1992. Monsoon and ENSO: Selectively interactive systems. Quarterly Journal of the Royal Meteorological Society 118: 877-926. 